\title{
A neurodegenerative perspective on mitochondrial optic neuropathies
}

\author{
Patrick Yu-Wai-Man ${ }^{1,2,3} \cdot$ Marcela Votruba $^{4,5} \cdot$ Florence Burté $^{1} \cdot$ \\ Chiara La Morgia ${ }^{6,7} \cdot$ Piero Barboni $^{8,9} \cdot$ Valerio Carelli ${ }^{6,7}$
}

Received: 21 May 2016 / Revised: 24 September 2016 / Accepted: 25 September 2016 / Published online: 30 September 2016

(C) The Author(s) 2016. This article is published with open access at Springerlink.com

\begin{abstract}
Mitochondrial optic neuropathies constitute an important cause of chronic visual morbidity and registrable blindness in both the paediatric and adult population. It is a genetically heterogeneous group of disorders caused by both mitochondrial DNA (mtDNA) mutations and a growing list of nuclear genetic defects that invariably affect a critical component of the mitochondrial machinery. The two classical paradigms are Leber hereditary optic neuropathy (LHON), which is a primary mtDNA disorder, and autosomal dominant optic atrophy (DOA) secondary to pathogenic
\end{abstract}

Electronic supplementary material The online version of this article (doi:10.1007/s00401-016-1625-2) contains supplementary material, which is available to authorized users.

Patrick Yu-Wai-Man

Patrick.Yu-Wai-Man@ncl.ac.uk

1 Wellcome Trust Centre for Mitochondrial Research, Institute of Genetic Medicine, Newcastle University, Newcastle upon Tyne, NE1 3BZ, UK

2 Newcastle Eye Centre, Royal Victoria Infirmary, Newcastle upon Tyne, NE1 4LP, UK

3 NIHR Biomedical Research Centre at Moorfields Eye Hospital and UCL Institute of Ophthalmology, London, EC1V 2PD, UK

4 School of Optometry and Vision Sciences, Cardiff University, Cardiff, UK

5 Cardiff Eye Unit, University Hospital of Wales, Cardiff, UK

6 IRCCS Institute of Neurological Sciences of Bologna, Bellaria Hospital, Bologna, Italy

7 Unit of Neurology, Department of Biomedical and Neuromotor Sciences (DIBINEM), University of Bologna, Bologna, Italy

8 Studio Oculistico d'Azeglio, Bologna, Italy

9 San Raffaele Scientific Institute, Milan, Italy mutations within the nuclear gene $O P A l$ that encodes for a mitochondrial inner membrane protein. The defining neuropathological feature is the preferential loss of retinal ganglion cells (RGCs) within the inner retina but, rather strikingly, the smaller calibre RGCs that constitute the papillomacular bundle are particularly vulnerable, whereas melanopsin-containing RGCs are relatively spared. Although the majority of patients with LHON and DOA will present with isolated optic nerve involvement, some individuals will also develop additional neurological complications pointing towards a greater vulnerability of the central nervous system (CNS) in susceptible mutation carriers. These so-called "plus" phenotypes are mechanistically important as they put the loss of RGCs within the broader perspective of neuronal loss and mitochondrial dysfunction, highlighting common pathways that could be modulated to halt progressive neurodegeneration in other related CNS disorders. The management of patients with mitochondrial optic neuropathies still remains largely supportive, but the development of effective disease-modifying treatments is now within tantalising reach helped by major advances in drug discovery and delivery, and targeted genetic manipulation.

Keywords Dominant optic atrophy · Leber hereditary optic neuropathy $\cdot$ Mitochondrial diseases . Neurodegenerative diseases · OPA1 - Retinal ganglion cell

\section{Introduction}

Mitochondrial diseases affect at least 1 in 4300 of the population and patients can present with either isolated or multisystemic organ involvement [58]. Despite these wide phenotypic manifestations, the eye is particularly vulnerable and over half of all patients will develop significant 
ocular complications, in particular involvement of the optic nerve [35, 143]. Unsurprisingly, the risk of blindness ranks high on patients' fears about the prognosis associated with their specific mitochondrial genetic defect [12, 74]. The optic nerve consists of the projecting axons from about 1.2 million retinal ganglion cells (RGCs) and the pathophysiological pathways that drive the selective loss of this highly specialised neuronal population are providing important new insights into the broader link between mitochondrial dysfunction and neurodegeneration within the central nervous system (CNS) [71]. The two classical mitochondrial optic neuropathies are Leber hereditary optic neuropathy (LHON) and autosomal dominant optic atrophy (DOA), which share overlapping clinical and pathological features, despite being caused by mitochondrial DNA (mtDNA) point mutations and a growing list of nuclear genetic defects, respectively. The defining neuropathological feature of LHON and DOA is the early loss of RGCs within the papillomacular bundle resulting in an expanding field defect, known as a scotoma, within the patient's central vision [52]. Interestingly, a subgroup of patients can develop a syndromic form of LHON and DOA that is characterised by prominent neurological deficits in addition to optic atrophy. This review will focus on the disease mechanisms that underpin the selective vulnerability of RGCs in mitochondrial optic neuropathies, but also how these could relate to the more extensive CNS neurodegeneration observed in patients with the more severe "plus" phenotypes. Crucially for patients and their families, there are currently limited treatment options and a number of strategies are being considered to prevent or halt neuronal loss in this group of disorders, all of which will need to be rigorously assessed for safety and efficacy.

\section{Leber hereditary optic neuropathy}

LHON is a primary mitochondrial genetic disorder that affects approximately 1 in 30,000 people in the population and three point mutations within the mitochondrial genome account for over $90 \%$ of cases, namely m.3460G $>$ A $(M T N D 1), \quad \mathrm{m} .11778 \mathrm{G}>\mathrm{A} \quad(M T N D 4)$ and $\mathrm{m} .14484 \mathrm{~T}>\mathrm{C}$ (MTND6) [87]. These three primary mtDNA mutations all affect complex I subunits and the disturbed flux of electrons along the mitochondrial respiratory chain results in impaired oxidative phosphorylation (OXPHOS) and increased levels of reactive oxygen species (ROS) [32]. LHON is the classical paradigm of a mitochondrial optic neuropathy and the preferential loss of retinal ganglion cells (RGCs) raises intriguing questions relating to tissue specificity and the secondary modulatory factors that dictate disease expression. The m.11778G $>$ A LHON mutation was the first mtDNA variant linked with human disease and despite three decades of intensive research, there are still several unsolved mysteries, in particular the marked incomplete penetrance and the sex bias associated with this mitochondrial disorder [134]. Penetrance can vary widely between families or even within different branches of the same family, but as a rule of thumb, the penetrance for a male LHON carrier is $~ 50 \%$ compared with $\sim 10 \%$ for a female LHON carrier [35, 143]. All the evidence so far points towards LHON being a complex disease that is determined by additional mitochondrial and nuclear genetic risk factors as well as environmental triggers such as smoking, which is associated with significantly increased risk of visual loss [66, 75, 88]. Oestrogens could also have a neuroprotective effect on RGCs and this feature could account, at least partly, for the relative protection of female LHON carriers against visual loss [55].

Patients with LHON typically present with bilateral subacute loss of central vision and the time course is defined by an expanding dense scotoma and a period of worsening visual acuities until a nadir is reached. In unilateral cases, the fellow eye usually converts within 3-6 months after first disease onset (Fig. 1). Spontaneous visual recovery can occur, usually in the first year, but the prognosis remains guarded with most patients remaining within the legal criteria for blind registration [97]. Limited post-mortem studies of optic nerves from patients with LHON confirm that the neuropathology is limited to the RGC layer [82, 116]. The rapid loss of RGCs in the acute phase of the disease is thought to be mediated via apoptotic pathways, but further work is needed to determine whether the primary site of the pathology lies within the cell body or the proximal unmyelinated axonal segments. The acute phase of LHON is characterised by the early loss of RGCs within the papillomacular bundle and this interesting pathological feature has been ascribed to their smaller than average axonal calibre [118]. The basis for this anatomical vulnerability has been modelled using a mathematical equation that integrates the surface area (energy demand) and volume (energy supply) ratio of the RGC axons, in relation to the amount of ATP needed to maintain axonal conduction [101]. It must be emphasised that there is no absolute experimental proof, but the greater surface area/volume ratio in smaller fibres is thought to result in a more limited mitochondrial bioenergetic reserve capacity and proportionally more ROS production compared with larger fibres [83].

\section{LHON plus phenotypes}

Although the neuropathological hallmark of LHON is dominated by the loss of RGCs within the inner retina, a subgroup of patients will develop extraocular features as part of a more severe LHON "plus" syndromic phenotype 

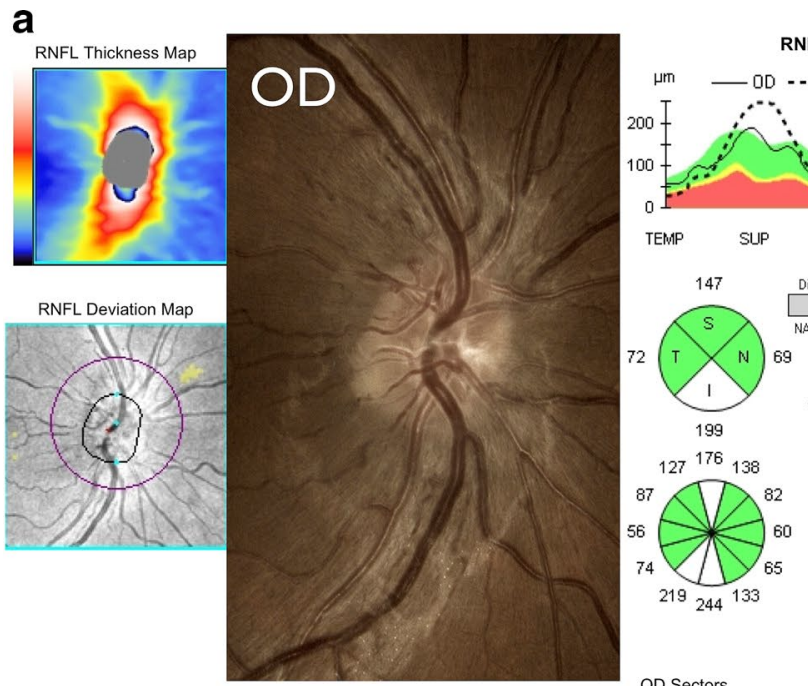

RNFL Thickness

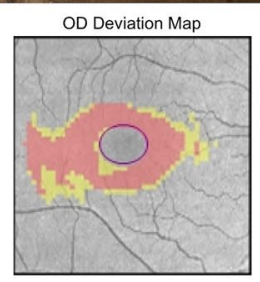

OD Sectors
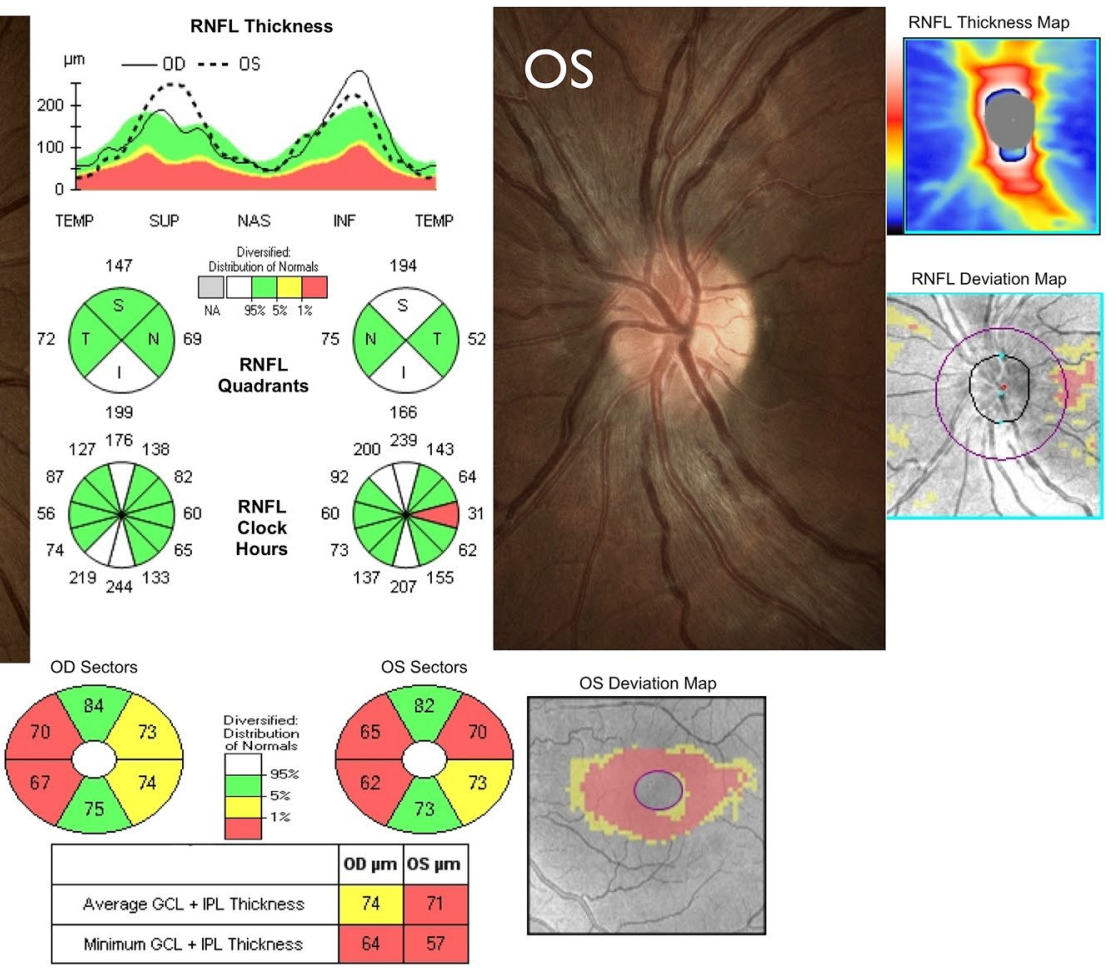

OS Deviation Map

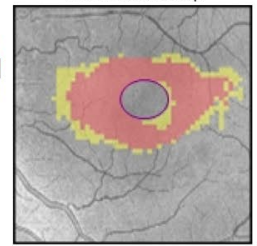

b
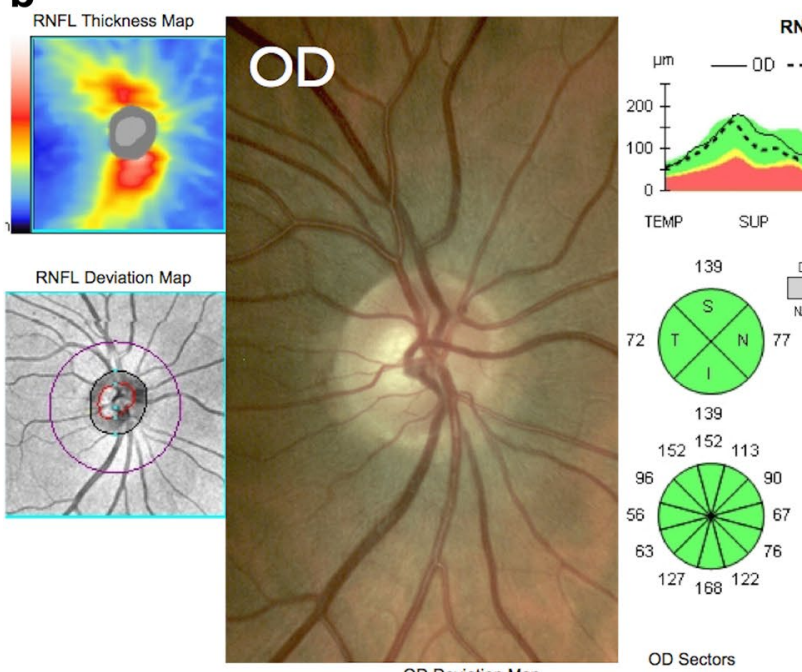

RNFL Thickness

$152^{152} 113$

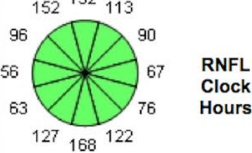

RNFL

Quadrants

OS Sectors
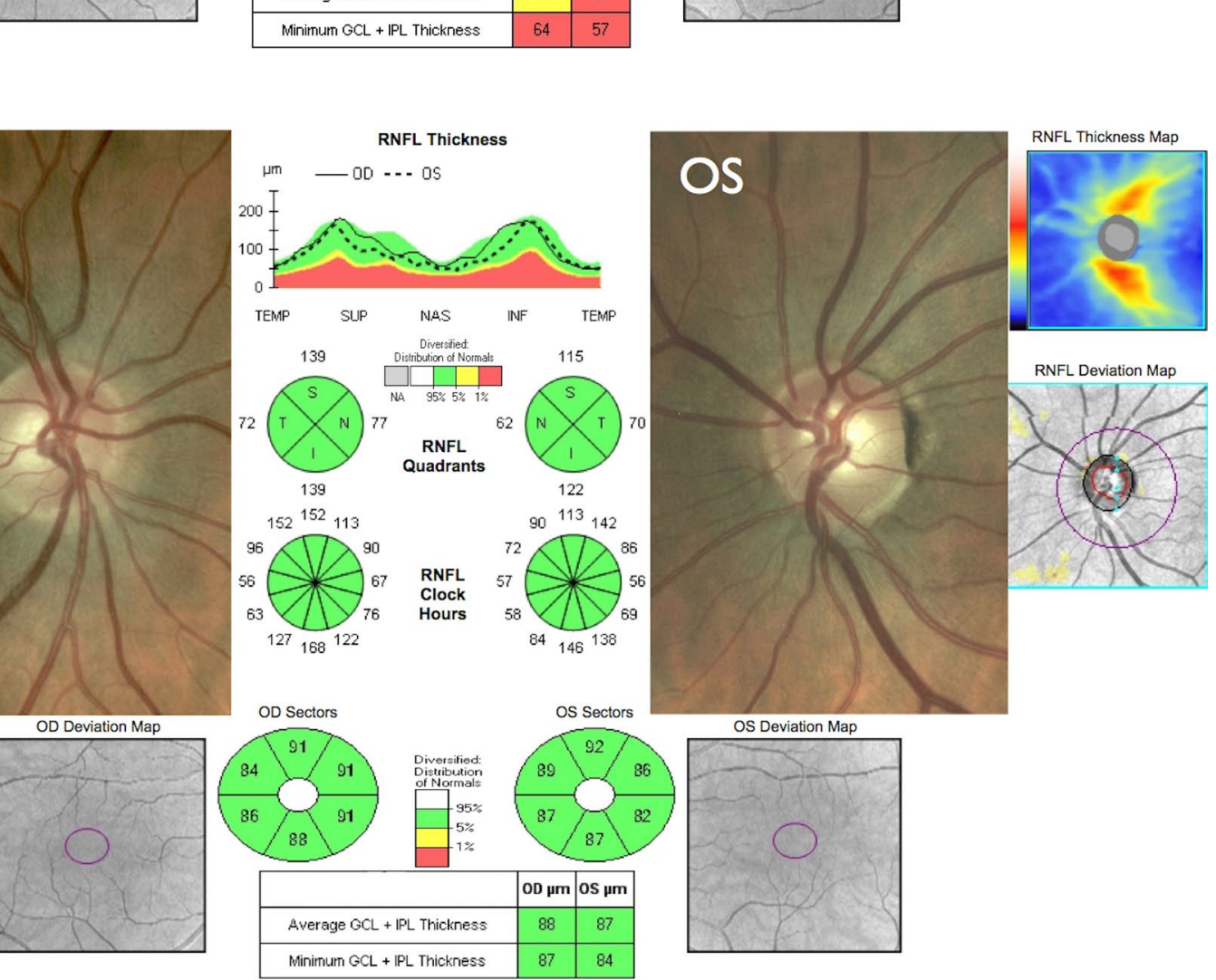

Fig. 1 Colour fundus and OCT findings in a patient with acute LHON compared with a healthy subject. a An 18-year-old man harbouring the m.3460G $>$ A mtDNA mutation who was in the acute stage of LHON with onset of visual loss of 1 and 2 months in the right (OD) and left eyes (OS), respectively. There are telangiectatic microangiopathy and swelling of the peripapillary retinal nerve fibre layer (RNFL) mainly involving the superior and inferior quadrants $(\mathrm{ONH}$ cube $200 \times 200$ protocol, Cirrus HD-OCT, Carl Zeiss Meditec). The left optic disc is showing early temporal pallor consistent with the RNFL thinning observed on OCT. The bottom panel shows macular ganglion cell layer thinning that is more evident in the left eye (Macular Cube $512 \times 128$ protocol). b Comparative images for a healthy subject. Please refer to the Supplementary Appendix for a more detailed explanation of the OCT measurements and their anatomical correlates 
[98]. It can be difficult to conclusively ascertain the link between a specific neurological feature and a LHON mtDNA mutation, but multiple independent case reports of patients developing similar syndromic phenotypes on the background of different pathogenic LHON mutations lend support to a true causal relationship, rather than mere coincidence. Dystonia and myoclonus are two movement disorders that have been consistently associated with the three primary LHON mutations and the development of these extraocular features clearly indicates the potential for a more generalised neurodegenerative process among at-risk LHON carriers [38, 92]. Rarer pathogenic mtDNA variants (m.4160T $>$ C, m.11696A $>\mathrm{G}$ and/or m.14596T $>\mathrm{A}$, and m.14459G $>$ A) in isolated families from Holland, Australia and North America have previously been linked with particularly severe LHON "plus" phenotypes complicated by spastic dystonia, ataxia, juvenile-onset encephalopathy, and psychiatric disturbances [35, 143]. Two mtDNA point mutations, m.3376G $>\mathrm{A}$ and $\mathrm{m} .3697 \mathrm{G}>\mathrm{A}$, with a pronounced inhibitory effect on complex I activity have also been identified in patients with an LHON-like optic neuropathy and features of the MELAS (mitochondrial encephalomyopathy, lactic acidosis, and stroke-like episodes) syndrome [24, 124].

The overlap between LHON and a multiple sclerosis (MS)-like illness (Harding disease) is a fascinating association that highlights a potential final common pathway linking mitochondrial dysfunction with neuronal loss and disease progression in acquired demyelinating disorders affecting the central nervous system (CNS). Although Harding disease was initially described in a group of 8 female LHON carriers harbouring the m.11778G $>$ A mutation, this striking combination of visual loss and more generalised CNS demyelination can affect both sexes, albeit with a slight female bias, and it has been reported with the m.3460G $>$ A and m.14484T $>C$ mutations as well (Fig. 2) $[63,81,100,104]$. The pattern of visual loss in LHONMS appears distinct from classical LHON and demyelinating optic neuritis, being marked by recurrent episodes of visual loss that can be associated with ocular pain, but with incomplete visual recovery and progression to registrable blindness in half of all patients [104]. Although there is conflicting evidence in the literature, on balance, it appears that a primary LHON mutation does not increase the risk of developing MS per se, but rather it modulates or potentiates the underlying neurodegenerative process in an individual who already has a pre-existing predisposition to developing clinically definite MS. As LHON-MS represents a relatively rare subgroup, there is no robust evidence base to guide treatment, but given the poor visual prognosis and the accumulating visual deficits associated with each attack, early disease-modifying therapy to prevent relapses and protect the optic nerve seems a pragmatic management approach.

Neuromyelitis optica (NMO) is a relatively rare form of CNS demyelinating disease among White Caucasians
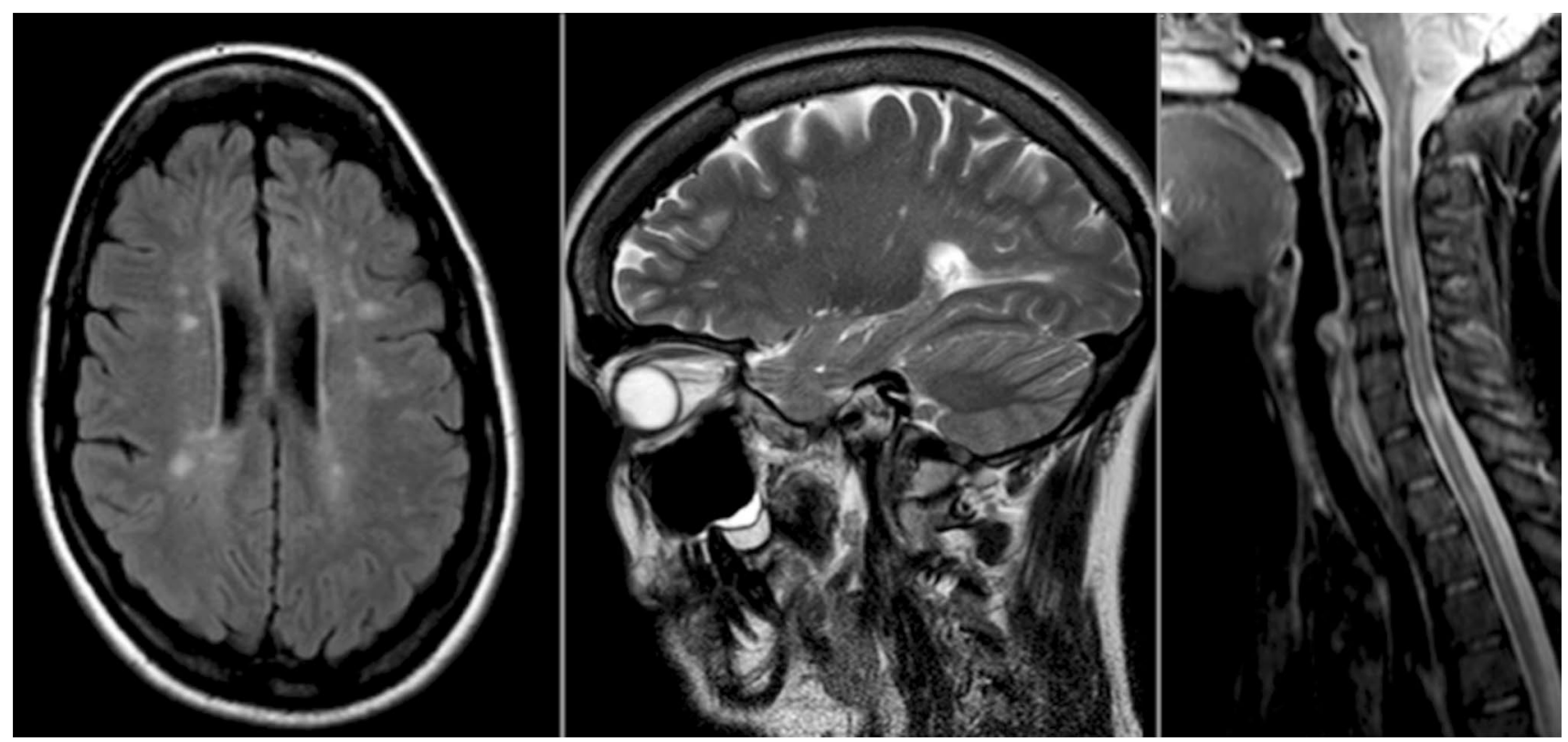

Fig. 2 LHON-MS overlap syndrome. T2 MRI images from a 27-year-old woman with episodes of recurrent optic neuritis over a 10 -year period associated with partial visual recovery. There are dis- seminated high-signal changes within the white matter regions of the brain and cervical spinal cord that are consistent with demyelination [105] 
with a prevalence that is $50-100$ times lower than that of MS [68]. The inflammatory process has a marked predilection for the optic nerves and the spinal cord and the neuropathology is closely linked with a specific autoantibody directed against aquaporin-4 (AQP4), which is the major water channel in the CNS [103, 138]. After decades of debate, clinicopathological studies have revealed striking differences between NMO and prototypic MS firmly establishing the two of them as distinct disease entities $[23,95,113]$. It is, therefore, interesting that in addition to Harding disease, patients with LHON have been described who developed a prominent spinal cord syndrome mimicking the radiological and pathological features of NMO [91, 122]. Additional research is clearly needed to further explore the interplay between a pathogenic LHON mutation, mitochondrial dysfunction and concurrent white matter CNS demyelinating disease $[30,85]$.

\section{Autosomal dominant optic atrophy}

In contrast to the subacute visual failure observed among young adult men in LHON, Poul Kjer described in 1959 a dominantly inherited bilateral optic neuropathy with an indolent course starting in early childhood [76]. Despite these major differences in presentation, DOA is also characterised by the marked vulnerability of RGCs within the papillomacular bundle, resulting in a central visual field defect, impaired colour vision and prominent temporal pallor of the optic disc on fundus examination (Fig. 3) [35, 143]. DOA affects at least 1 in 25,000 people in the population and it is the most common inherited optic neuropathy encountered in clinical practice [142]. The true prevalence is likely to be higher due to the marked variability in clinical expression and disease progression both within and between families. Some mutation carriers present with very poor visual function from birth with optic nerve hypoplasia, whereas others are visually asymptomatic and they are only detected as part of familial contact tracing [15, 42]. The natural history of the disease can also be highly variable with slowly progressive, sometimes step-like deterioration of visual function over time in most patients, whereas for others, visual acuity reaches a plateau in early to mid-adulthood without any further significant deterioration [41, 142]. Although the pattern of visual failure in DOA is relatively less severe compared with LHON, the majority of patients are eventually registered legally blind and they, therefore, need to be counselled appropriately.

The majority (60-70\%) of patients with DOA harbour pathogenic mutations in the nuclear gene OPAl that

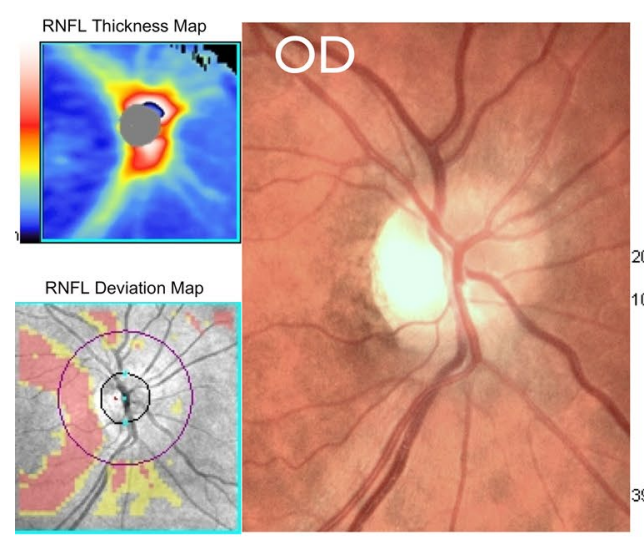

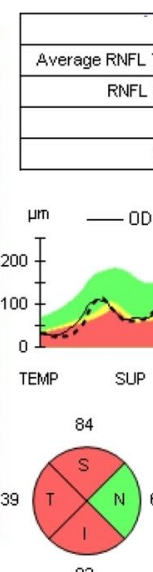

Sectors

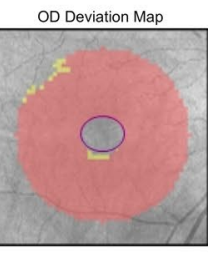

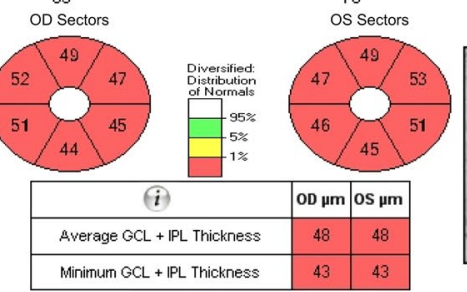
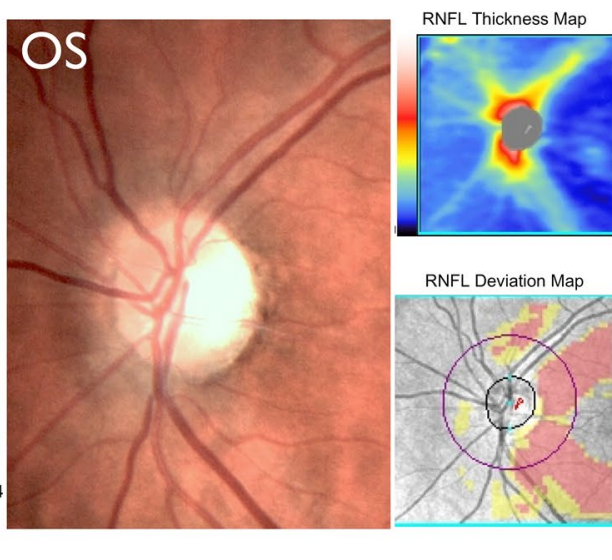

os Deviation Map

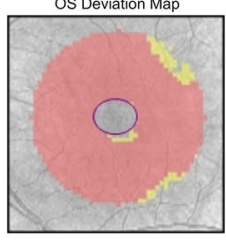

Fig. 3 Colour fundus and OCT findings in DOA. The images were obtained from a 20 -year-old woman with progressive visual loss starting in early childhood and confirmed to harbour a pathogenic OPAl mutation. There is prominent temporal optic disc pallor and marked RNFL thinning except in the nasal quadrant, which is relatively spared. The disc area analysis reveals small optic discs in both eyes. The bottom panel shows pronounced macular ganglion cell layer thinning in all sectors. Please refer to the Supplementary Appendix for a more detailed explanation of the OCT measurements and their anatomical correlates 
encodes for a mitochondrial inner membrane protein with multifunctional properties [4, 47]. Over 250 OPAl mutations have been reported and these can be grouped into two major categories depending on whether they are predicted to cause disease due to haploinsufficiency (deletions, insertions, splice site and nonsense mutations) or a possible dominant-negative mechanism (missense mutations) [50, 53]. More recently, heterozygous mutations in a number of nuclear genes have been identified in patients with DOA, including dominant $O P A 3$ mutations in families segregating optic atrophy and early onset cataracts [111]. The OPA3 protein is a mitochondrial outer membrane protein with pro-fission properties and the loss of RGCs has been linked to disturbed mitochondrial dynamics [28]. Interestingly, DRP1 is also a pro-fission cytosolic protein that is recruited to the mitochondrial outer membrane, and both $S P G 7$ and AFG3L2 encode for mitochondrial AAA proteases that operate as oligomeric complexes to regulate the post-translational processing of OPA1 [39, 78, 135]. Rather strikingly, with the exception of WFS1, which encodes for an endoplasmic reticulum protein, all proteins associated with DOA are closely involved in regulating mitochondrial dynamics, pointing towards a key biological pathway essential for RGC maintenance and survival (Table 1) $[28,110]$. Even with the advent of next-generation whole exome and genome sequencing, a proportion of patients with optic atrophy and a clear-cut autosomal dominant pattern of inheritance still remain genetically undefined and DOA is proving to be much more genetically heterogeneous than originally considered.

\section{DOA plus phenotypes}

Optic atrophy is the defining feature of DOA, but a specific missense mutation within the $O P A 1$ gene, c. $1334 \mathrm{G}>\mathrm{A}$ (p.Arg455His), has been consistently associated with sensorineural deafness in a number of families [6, 144]. The clinical manifestations observed in OPAl disease have now expanded further to include chronic progressive external ophthalmoplegia (CPEO) and other extraocular features such as ataxia, myopathy and peripheral neuropathy [7, $13,65]$. In a large multicentre study of 104 patients with DOA plus phenotypes from 45 independent families, up to $20 \%$ of familial OPAl carriers developed multisystemic neuromuscular complications and the risk was significantly increased among those harbouring missense OPAI mutations, consistent with a putative dominant-negative effect [144]. Rather unexpectedly, analysis of muscle biopsies obtained from this group of patients revealed multiple mtDNA deletions and the presence of high levels of cytochrome $c$ oxidase (COX)-deficient muscle fibres, some of which had marked mitochondrial proliferation in the form of ragged-red fibres [125, 144]. The accumulation of mtDNA deletions is a fascinating observation that could be due to the accelerated clonal expansion of these somatic mutations to sufficiently high levels to trigger a biochemical COX defect [102, 146]. CPEO is a classical manifestation of mitochondrial disease and in keeping with the propensity of extraocular muscles to accumulate somatic mtDNA mutations at a faster rate compared with skeletal muscle, it is perhaps not surprising that about half

Table 1 Nuclear mitochondrial disorders with prominent optic nerve involvement

\begin{tabular}{lllll}
\hline Inheritance & Locus & Gene & OMIM & Phenotype \\
\hline Dominant & $1 \mathrm{p} 36.2$ & MFN2 & 601,152 & Hereditary motor and sensory neuropathy type 6 (HMSN-6, CMT2A) \\
& 3q28-q29 & OPA1 & 165,500 & Isolated optic atrophy and syndromic dominant optic atrophy (DOA plus) \\
& 4p16.1 & WFS1 & 614,296 & Wolfram syndrome spectrum disorders \\
& $12 \mathrm{p} 11.21$ & DRP1 & 614,388 & Optic atrophy and abnormal brain development \\
Recessive & 19q13.2-q13.3 & OPA3 & 165,300 & Autosomal dominant optic atrophy and early-onset cataracts (ADOAC) \\
& 3q26.33 & DNAJC19 & 610,198 & DCMA syndrome \pm optic atrophy \\
& 4p16.1 & WFS1 & 222,300 & Wolfram syndrome 1 \\
& 4q24 & CISD2 & 604,928 & Wolfram syndrome 2 \\
& 5q.22.1 & SLC25A46 & 616,505 & Optic atrophy \pm peripheral neuropathy/cerebellar syndrome \\
& 6q21 & RTN4IP1 & 616,732 & Optic atrophy \pm cerebellar syndrome/mental retardation/epilepsy \\
& 9q13-q21.1 & FXN & 229,300 & Friedreich ataxia \\
& 11q14.1-q21 & TMEM126A & 612,989 & Optic atrophy \pm auditory neuropathy \\
& 12q24.31 & C12orf65 & 615,035 & Optic atrophy \pm spastic paraplegia/peripheral neuropathy \\
& 16q24.3 & SPG7 & 607,259 & Hereditary spastic paraplegia type 7 (HSP-7) \\
& 19q13.2-q13.3 & OPA3 & 258,501 & Type III 3-methylglutaconic aciduria (Costeff syndrome) \\
& 22q13.2 & ACO2 & 616,289 & Optic atrophy \pm cerebellar syndrome/encephalopathy \\
& Xq22.1 & TIMM8A & 304,700 & Mohr-Tranebjaerg syndrome \pm optic atrophy
\end{tabular}


of all patients with DOA plus phenotypes develop ptosis and ophthalmoplegia in later life $[59,145]$.

Similar to Harding disease in LHON, OPAl mutation carriers can also develop an MS-like illness where the optic atrophy occurs on the background of a more disseminated inflammatory process with neuroradiological and serological features, consistent with MS [133, 147]. It is intriguing that both LHON and DOA share this specific association and the contribution of the underlying pathogenic mtDNA or OPAl mutation in driving CNS neurodegeneration deserves further study. The association of optic atrophy with spastic paraplegia, resembling cases that fit the historical description of Behr syndrome, has been well described in several unrelated OPA1 mutation carriers [26, 37, 90]. The development of this syndromic form of DOA has been ascribed to the deleterious synergistic consequences of compound heterozygous OPAl mutations, in particular the recurrent c.1146A $>\mathrm{G}$ (p.Ile382Met) missense mutation, which can occur in combination with a deep intronic mutation [25]. Remarkably, two Italian families carrying different $O P A 1$ missense mutations have been reported with an atypical combination of parkinsonism, dementia and CPEO, but with only subclinical optic neuropathy [34]. More recently, a compound homozygous OPAl mutation has been identified for the first time in two affected Jewish sisters from consanguineous parents who developed a fatal infantile encephalomyopathy with hypertrophic cardiomyopathy and optic atrophy [123]. However, instead of multiple mtDNA deletions, the muscle biopsy from one sister showed marked mtDNA depletion. The expanding clinical and genetic heterogeneity linked to DOA plus phenotypes only serves to emphasise the more global neurodegenerative impact of pathogenic OPAl mutations that can extend far beyond the inner retina and the anterior visual pathways. There is now a considerable body of evidence linking mitochondrial dysfunction with late-onset neurodegenerative disorders, such as Alzheimer disease and Parkinson disease, indicating a common pathological thread and a close relationship with mitochondrial structure, function and localisation [28].

A syndromic form of optic atrophy reminiscent of DOA plus can arise from dominant mutations in the MFN2 gene, which encodes for a mitochondrial outer membrane protein [109, 115]. MFN2 coordinates mitochondrial fusion by working in close tandem with its fellow fusogenic protein, OPA1, and analogous to the observation in muscle biopsies from patients carrying OPA1 mutations, MFN2 mutations can also precipitate mtDNA instability with either the accumulation of multiple mtDNA deletions or mtDNA depletion. MtDNA maintenance is clearly intrinsically linked to the delicate balance between mitochondrial fusion and fission and adding further weight to this hypothesis, $S P G 7$ and $A F G 3 L 2$ mutations have now been reported in patients with ataxic disorders complicated by CPEO and optic atrophy, and with evidence of multiple mtDNA deletions in skeletal muscle biopsy specimens [57, 105]. Nuclear genes that are directly or indirectly involved in regulating mitochondrial dynamics and the faithful replication of the mitochondrial genome can, therefore, lead to varying degrees of CNS neurodegeneration, but with the optic nerve being invariably the most sensitive affected end organ [31].

\section{Other mitochondrial optic neuropathies}

Autosomal recessive and X-linked optic neuropathies are relatively rare, but an increasing number of disease causing genes are being identified with wider access to molecular genetic testing and next-generation sequencing platforms (Table 1). TMEM126A, which encodes for a mitochondrial inner membrane protein of unclear function, was the first gene to be found in patients with non-syndromic recessive optic atrophy, although it can also occur in combination with peripheral neuropathy in some mutation carriers [62]. Other genes associated with both isolated and syndromic forms of recessive optic atrophy include: (1) ACO2, which encodes for an enzyme of the tricarboxylic acid cycle [93]; (2) RTN4IP1, which encodes for a mitochondrial outer membrane protein that interacts with the endoplasmic reticulum protein RTN4 (or NOGO) to regulate neuronal dendritic branching [9]; (3) WFSI (Wolfram syndrome 1), which encodes for Wolframin, a transmembrane endoplasmic reticulum protein that plays a critical role in calcium homeostasis and interorganellar cross-talk at mitochondriaassociated membranes (MAMs) [28, 126]; and (4) CISD2 (Wolfram syndrome 2), which encodes for Miner 1, a redox-active iron-sulphur cluster protein that regulates the unfolded protein response and calcium homeostasis [136]. The molecular elucidation of both forms of Wolfram syndrome has uncovered the intimate dynamic interactions between mitochondria and the endoplasmic reticulum, and how dysfunction in one compartment can detrimentally disturb the other, and vice versa.

The occurrence of visual pathway involvement has become much better appreciated in the inherited ataxias and peripheral neuropathy syndromes. Friedreich Ataxia (FRDA) is the most common form of hereditary ataxia and it is due to recessive mutations in the $F X N$ gene, which encodes for a mitochondrial protein involved in the biosynthetic pathways of iron-sulphur clusters [143]. The latter are essential components of aconitase and the mitochondrial respiratory chain complexes I, II and III, and their combined dysfunction probably contributes to the development of optic neuropathy, which is now a well-recognised feature of FRDA [51]. Costeff Syndrome or type III 3-methylglutaconic aciduria (MGA) is a rare neurodegenerative disorder 
characterised by ataxia, spastic paraplegia, extrapyramidal dysfunction, cognitive deficits and optic atrophy, and it is almost exclusively seen in patients of Iraqi Jewish descent harbouring recessive $O P A 3$ mutations [10].

Charcot-Marie-Tooth (CMT) disease is one of the most common inherited neurological disorders, affecting approximately 1 in 2500 people in developed countries. A long list of causative genes have been identified, including MFN2, which can cause both recessive and dominant axonal CMT2A. In one particular subtype of CMT2A, referred to as hereditary motor and sensory neuropathy type 6 (HMSN6), dominant MFN2 mutations result in visual failure secondary to optic atrophy in addition to the more typical axonal peripheral neuropathy $[149,150]$. Prompted by this phenotypic association, other inherited forms of optic atrophy associated with CMT disease have been recently described with recessive mutations in SLC25A46 [1] and C12orf65 [107]. It should also be noted that both SLC25A46 and C12orf65 mutations can also result in a much more severe neurodegenerative Leigh-like presentation $[11,64,69]$.

The Mohr-Tranebjaerg syndrome (deafness-dystoniaoptic atrophy) is associated with recessive mutations affecting the TIMM $8 A$ gene on the X-chromosome, which encodes for a translocase of the mitochondrial inner membrane (TIMM) [70]. Visual failure in this disorder is thought to be due to global involvement of the visual pathways, extending as far back as the visual cortex [130]. A similar mechanism of altered protein import through the mitochondrial inner membrane has also been postulated for the DCMA (dilated cardiomyopathy with ataxia) syndrome, which is caused by mutations in the DNAJC19 gene, and optic atrophy has been reported in some cases [45].

\section{Neurodegeneration: histopathological studies}

The number of post-mortem studies for patients with mitochondrial optic neuropathies is limited and some historical reports date back to the pre-molecular era $[2,116]$. For LHON, histopathological studies of multiple tissues including the retina, optic nerve and brain are rare and none have been performed during the acute stage of the disease [36]. Notwithstanding these practical limitations, there is severe loss of RGCs and marked thinning of the retinal nerve fibre layer (RNFL), but the remaining retinal structure is otherwise preserved [73, 119]. Electron microscopy carried out on optic nerve cross-sections has also highlighted prominent demyelinating features in the chronic stage of LHON with only a thin covering of myelin found around the remaining axons (Fig. 4) [36]. Comprehensive brain histopathology has been reported for an affected m.14484T $>C$
LHON carrier with an MS overlap syndrome and a spectrum of neuropathological changes was observed, including demyelinating plaques within the brain white matter and optic nerves, and prominent vacuolation and cystic necrosis throughout the CNS [81]. As expected from the clinical features, post-mortem studies of optic nerves from patients with DOA confirmed the preferential loss of RGCs with evidence of axonal demyelination and gliosis [72, 77]. In contrast to the widespread loss of RGCs in patients with LHON and DOA, an evolutionary ancient RGC subtype that expresses the photopigment melanopsin (mRGCs) seems relatively immune to mitochondrial dysfunction and impaired mitochondrial dynamics. These mRGCs are highly specialised circadian photoreceptors that project to the hypothalamus and their preservation in LHON and DOA likely explains the maintenance of the pupillary light reflex even in those patients with severe visual impairment (Fig. 4) [82, 96].

\section{Neurodegeneration: in vivo imaging}

Major advances in bioimaging technology have allowed unprecedented high-resolution images of the brain, visual pathways and retinal structures to be captured for analysis. In vivo techniques such as magnetic resonance spectroscopy (MRS) and optical coherence tomography (OCT) are non-invasive and well tolerated, and they provide standardised tools that have been used to document the chronology and pattern of tissue loss in both the acute and chronic stages of LHON [19, 21, 121]. Based on longitudinal OCT studies, swelling of the RGC axons along the inferotemporal segment of the optic disc seems to occur prior to the onset of visual loss and following disease conversion, a wave of RNFL swelling then spreads circumferentially to involve the remaining quadrants (Fig. 1) [16]. As optic atrophy ensues, there is global thinning of the peripapillary RNFL although some patients can exhibit relative sparing of the nasal quadrant in the chronic stage. High-resolution spectral domain macular OCT imaging has provided further insight into the pattern of RGC loss in LHON. Interestingly, in patients presenting with first eye involvement, the macular ganglion cell and inner plexiform layer (GCIPL) and the macular RNFL already showed pathological thinning in the presymptomatic stage about 6 weeks before the onset of visual loss in the fellow eye. Maximal GC-IPL thinning was reached by 6 months and this OCT parameter could, therefore, prove to be a more sensitive biomarker of optic nerve damage compared with peripapillary RNFL measurements where progressive thinning continues until at least 12 months after the first onset of visual loss [14].

OCT studies in cohorts of patients harbouring pathogenic OPA1 mutations have shown a differential pattern 


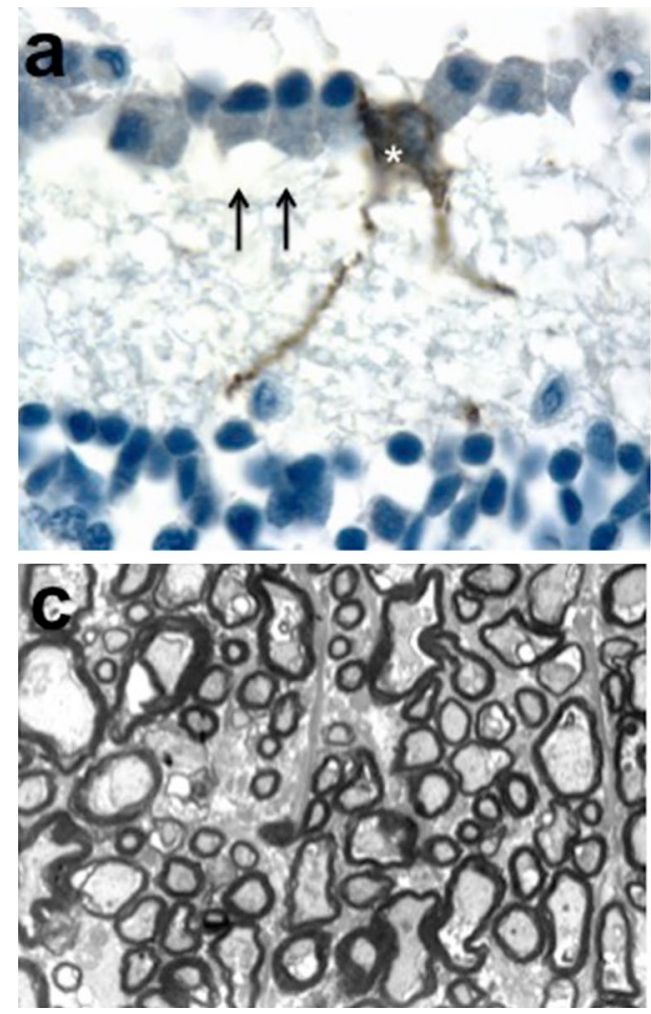

Fig. 4 Melanopsin-expressing retinal ganglion cells and myelin ultrastructure. a Retinal cross-sections from a healthy control individual were stained with antibody against melanopsin. The inner retina shows the ganglion cell layer with retinal ganglion cells (arrows) and one melanopsin-expressing retinal ganglion cell (asterisk). b The inner retina from a patient with LHON reveals a melanopsin-expressing retinal ganglion cell (asterisk) in the complete absence of other

of RNFL thinning, which was more severe in the temporal quadrant and less pronounced in the nasal quadrant (Fig. 3) [20, 140]. Importantly, OPA1 mutations were associated with a significantly smaller optic nerve head and although speculative, this congenital hypoplasia could result from dysregulated apoptosis in early development and an accelerated loss of RGCs in utero. As for LHON, macular GCIPL thickness measurements could prove a more useful structural biomarker that correlates better with visual acuity loss compared with peripapillary RNFL values [18]. Another observation made possible by high-resolution OCT imaging is the documentation of microcystic macular changes in the inner nuclear layer of patients with LHON and DOA $[17,29]$. These retinal abnormalities are not associated with leakage on fluorescein angiography and they have been attributed to focal retinal schisis induced by vitreous traction on the background of severe RNFL atrophy. Similar microcystic macular changes have previously been described in patients with demyelinating optic neuritis and a possible aetiological link was made with the severity of the underlying inflammatory process [54]. More recently,

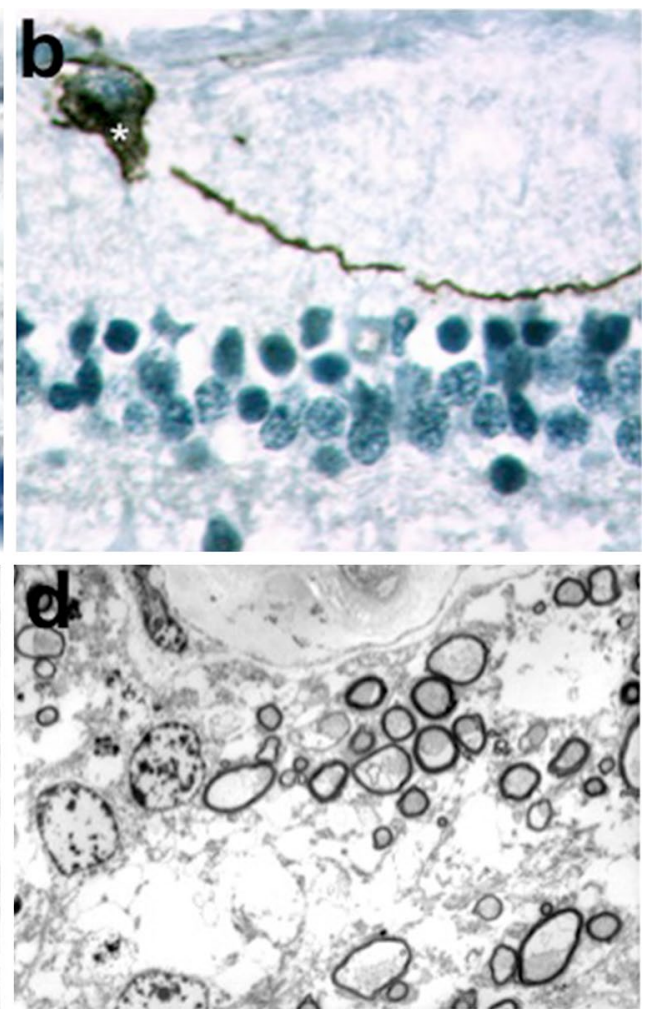

retinal ganglion cells. c Electron micrograph of optic nerve crosssections from a healthy control individual showing densely packed axons with variable axonal calibre and normal myelin thickness. d A representative illustration from a patient with LHON highlights the dramatic depletion of axons with a thin myelin coating around the surviving axons

lamination of the outer plexiform layer has been observed in patients with optic atrophy caused by dominant, but not recessive, WFS1 mutations, and this peculiar OCT characteristic could be due to Müller cell dysfunction and disturbed calcium homoeostasis [86].

MRI tractography studies indicate that the loss of RGCs in the anterior visual pathway could result in transsynaptic degeneration that extends from the lateral geniculate nucleus to the optic radiations, as reported previously in other optic neuropathies such as demyelinating optic neuritis and glaucoma [22, 89]. More widespread microstructural white matter changes in mitochondrial optic neuropathies have also become more clearly apparent with the application of high-resolution MRI scanners and diffusion tensor (DT) imaging protocols to study cohorts of patients with LHON and OPA1-related DOA, which is consistent with the known white matter sensitivity to mitochondrial respiratory chain dysfunction [89, 94, 112, 114]. Furthermore, the pattern of DT MRI abnormalities and the lowered diffusivity in the white matter skeleton of the cerebellum, brainstem, thalamus and fronto-occipital-temporal lobes 
could reflect increased fragmentation of the mitochondrial network and altered neuronal dendritic arborization [112]. Proton magnetic resonance spectroscopy ( $\left.{ }^{1} \mathrm{H}-\mathrm{MRS}\right)$ has also shown that raised lactate and reduced creatine $(\mathrm{Cr})$ and $\mathrm{N}$-acetylaspartate (NAA) levels can occur not only in areas of abnormal signal changes, but also in normal appearing white matter regions, indicative of a generalised mitochondrial metabolic deficit within the CNS [99, 114]. In terms of their clinical relevance, the neuroradiological changes observed in patients with mitochondrial optic neuropathies could prove useful surrogate biomarkers for the spectrum of white matter neuropathological abnormalities observed in mitochondrial disease, which can range from mild atrophy to extensive vacuolation with a sieve-like appearance depending on the severity of the underlying mitochondrial dysfunction [132].

\section{Disease mechanisms}

The unique susceptibility of RGCs in mitochondrial optic neuropathies still remains a puzzling mystery and although several hypotheses have been put forward, none has been conclusively demonstrated $[35,143]$. The highly specialised anatomical and physiological properties of RGCs are likely to be relevant, namely their relatively high metabolic requirements due to sustained spiking activity; the constant exposure to potentially damaging light; the sharp 90-degree bend as their axons exit the eye at the lamina cribosa; and the relatively long unmyelinated intraocular portion that necessitates a high density of packed mitochondria for efficient signal conduction $[8,27]$. Faced with these multiple constraints, it should therefore not come as a surprise that mitochondria in neurones have evolved specific adaptations to survive in such a challenging environmental niche. The RGC body is located within the inner retina and its dense dendritic arborization together with its long axonal projection to the lateral geniculate nucleus places peculiar demands on cellular mitochondria. They must be able to cluster at synapses to deliver sufficient quantities of ATP locally and altering the delicate balance between mitochondrial fusion and fission is essential to meet the cell's fluctuating bioenergetic demands, in addition to supporting bidirectional transport along dendrites and axon [31]. Clearly, the disruption of critical pro-fusion proteins, such as OPA1 and MFN2, or a direct impact on complex I subunits as in LHON will have profound negative consequences on mitochondrial function with reduced ATP production and elevated ROS levels [28]. There is still an ongoing debate whether the determining factor that drives RGC loss in mitochondrial optic neuropathies is primarily due to a bioenergetic crisis or toxic ROS levels, or possibly with both factors having a synergistic deleterious effect [83].
To further disentangle the complex neurodegenerative pathways that underpin this group of inherited optic nerve disorders, a number of in vitro approaches have been employed and the effort of several research groups worldwide has led to the generation of faithful animal models for both LHON and DOA [28, 84]. Heterozygous $\mathrm{Opal}^{+/-}$mutant mice recapitulate the progressive RGC loss and optic nerve degeneration observed in the human form of the disease and the experimental data indicate that multiple pathways are involved that contribute to impaired mitochondrial oxidative phosphorylation, disturbed mitochondrial dynamics, increased ROS generation and, ultimately, a heightened susceptibility to undergo apoptosis [3, 40, 46, 120]. Immunolabelling of retinal flat-mount preparations obtained from $\mathrm{Opal}^{+/-}$mutant mice showed dendritic pruning of ON-centre RGCs from 10 months of age with a significant reduction in total dendritic length and surface area (Fig. 5). Synaptic connectivity imaged after biolistic labelling of RGCs also showed reduced synaptic density on the distal ends of the dendritic tree [137]. Among the Opal mouse models that have been established, there is also a suggestion that some of the mutant mice can develop extraocular features analogous to the more severe syndromic "plus" phenotypes observed in a proportion of patients with DOA. In addition to inner retinal and optic nerve degeneration, more widespread neuropathological and psychophysical abnormalities have been noted in subgroups of $\mathrm{Opal}^{+/-}$mutant mice, including enlarged lateral ventricles within the brain, disorganised myofibres in skeletal and cardiac muscle, locomotive and ataxic gait disturbance, and decreased auditory brainstem responses [4, 40, 120].

Other cellular mechanisms that have gained increasing attention in the context of mitochondrial optic neuropathies are mtDNA maintenance and mitophagy, and the cross-talk with the endoplasmic reticulum at MAM interfaces $[28,129]$. The accumulation of somatic mtDNA deletions in post-mitotic tissues of patients carrying OPAI mutations points towards an impaired mtDNA replication machinery and there is a suggestion that OPA1 could be part of the physical structure that anchors nucleoids to the mitochondrial inner membrane [48]. Another possible explanation for the clonal expansion of somatic mtDNA deletions is the inability to remove these dysfunctional mtDNA species through mitophagy $[34,102]$. The occurrence of optic atrophy in the context of pathogenic MFN2, WFS1 and CISD2 mutations provides strong supportive evidence that RGC survival is detrimentally affected as a result of impaired interactions between the mitochondrial network and the endoplasmic reticulum, especially if there is disturbed calcium flux between these compartments [28]. Although much has been learnt over the years, all the above observations still do not fully explain the marked clinical 


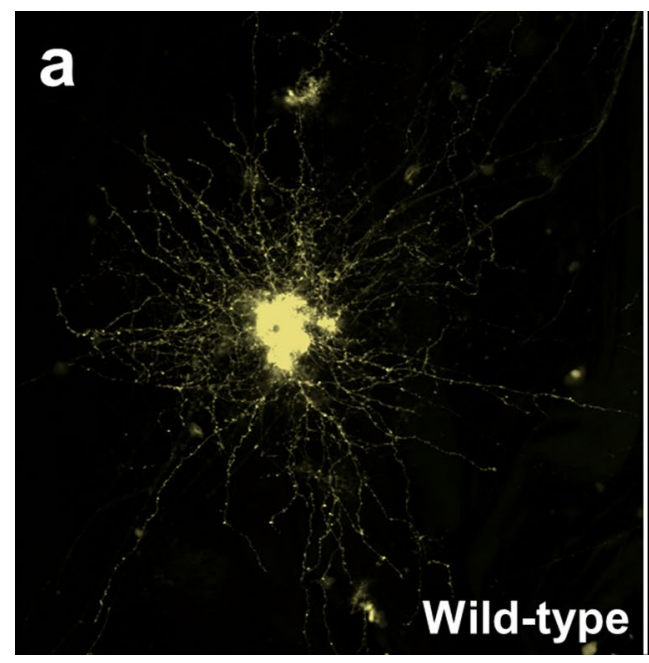

Fig. 5 Dendropathy in a mouse model of dominant optic atrophy. a Flat-mounted retinas were labelled with the fluorescent marker DiI and individual RGCs were imaged with confocal microscopy. A representative RGC from a 16-month-old wild-type mouse is shown that demonstrates the extensive arborization of the dendritic tree. $\mathbf{b}$ An

variability and tissue specificity seen in mitochondrial optic neuropathies, and dissecting these complex mechanistic questions holds the key to more effective targeted therapeutic strategies [141]. Rightly so, the early focus has been on the molecular genetics, but now there is an urgent need to capitalise on the greater availability of more sophisticated technological platforms to compare the transcriptomic, proteomic and metabolomic profiles between different phenotypic groups to look for potential clues or biomarkers that might explain the variable disease penetrance and prognosis for patients with mitochondrial optic neuropathies [44, 131].

\section{Therapeutic strategies}

The management of patients with mitochondrial optic neuropathies remains largely supportive with the provision of visual rehabilitation and genetic counselling [106, 148]. There are a number of technical and logistical challenges in developing effective disease-modifying treatments aimed at rescuing RGCs, namely the need to bypass the blood brain barrier to achieve a high enough local concentration of the drug; the limited therapeutic window posed by the massive early loss of RGCs in subacute disorders such as LHON; the limited availability of sensitive optic nerve biomarkers; and, crucially, the substantial financial resources needed to conduct an adequately powered treatment trial. Despite these difficulties, the eye is an easily accessible organ for direct surgical intervention and it benefits from relative immune privilege.

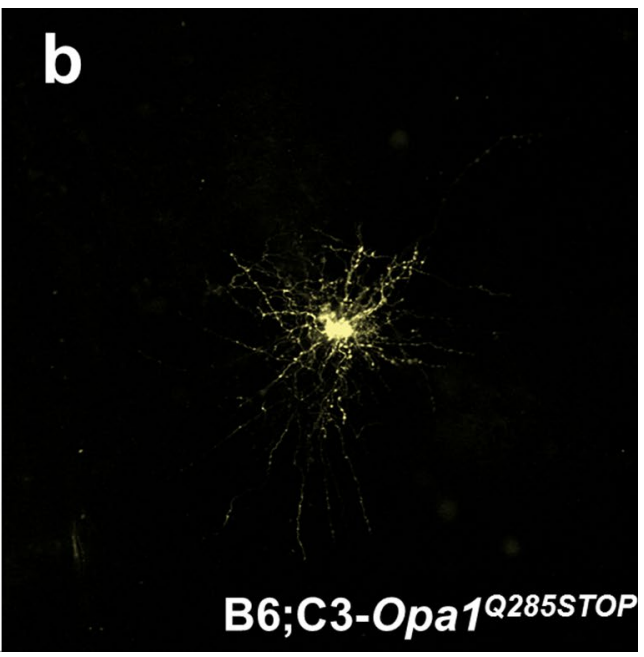

age-matched RGC from a B6;C3-Opal ${ }^{\mathrm{Q} 285 \mathrm{STOP}}$ mutant mouse harbouring a nonsense mutation in the $O P A 1$ gene. There is marked dendritic pruning characterised by a reduction in total dendritic length and field area

One obvious therapeutic approach is to improve the flux of high energy electrons along the mitochondrial respiratory chain and bypass any blockage in more proximal complexes. Ubiquinone is a fat-soluble molecule present at a very high concentration within the inner mitochondrial membrane and it has the advantageous property of transferring electrons efficiently from complexes I and II to complex III [60]. Co-enzyme Q10 $\left(\mathrm{CoQ}_{10}\right)$ is a synthetic ubiquinone analogue and despite the limited evidence base, it is frequently prescribed to patients with mitochondrial disease. Idebenone and EPI-743 are newer generation shorter-chain analogues of ubiquinone and, unlike $\mathrm{CoQ}_{10}$, they can cross the blood brain barrier, which makes them theoretically more potent as antioxidants [106]. There is supporting evidence that idebenone can improve the visual prognosis, albeit, partially, in a subgroup of patients that are treated relatively early in the acute stage of LHON [33, 79, 80]. EPI-743 has also shown promise in a small case series of five patients with acute LHON treated within 90 days of disease conversion, but a randomised placebo-controlled trial is needed to fully explore its true therapeutic potential [117]. In addition to antioxidants, boosting mitochondrial biogenesis and ATP synthesis is an attractive complementary strategy that could help rescue failing neuronal cells from apoptotic cell death. A number of drugs, such as bezafibrate, rosiglitazone, 5-aminoimidazole-4-carboxamide ribonucleoside (AICAR), acetyl-L-carnitine (ALCAR), vitamin B3, and oestrogen-like molecules, have been identified as effective inducers of mitochondrial proliferation under conditions of metabolic stress and their effectiveness in rescuing the optic nerve phenotype or the neurological 
manifestations of LHON and DOA deserve to be studied further [106, 148].

Direct mitochondrial gene therapy is challenging due to the constraints imposed by the organelle's physical structure and the presence of a relatively impervious inner mitochondrial membrane. A possible approach to circumvent these technical difficulties is allotopic gene expression where the gene of interest is transferred into the nuclear genome and the replacement protein product is engineered with a specific targeting sequence that facilitates its uptake into the mitochondrial compartment [139]. Promising pre-clinical data based on in vitro and rodent models have resulted in the recent launch of pivotal clinical trials for patients harbouring the $\mathrm{m} .11778 \mathrm{G}>\mathrm{A}$ mutation that involves the intravitreal injection of a modified adenoassociated virus (AAV) vector carrying the replacement MTND4 subunit gene (NCT02652767, NCT02652780 and NCT02161380, https://clinicaltrials.gov/ct2/home, accessed on 28 August 2016) [49, 61]. An alternative, but complementary, approach is to modify the AAV construct to carry a gene whose protein product has a neuroprotective effect and enhances the survival of dysfunctional neurones. Proof of principle has been demonstrated with the overexpression of SOD2, which encodes for superoxide dismutase and serves to boost the cell's antioxidant defence mechanisms [108]. These more generic neuroprotective approaches are attractive as they could be applied not only to rescue RGCs, but also other central neuronal populations in patients manifesting the more generalised "plus" phenotypes. There are still multiple challenges that need to be overcome to achieve a higher efficiency of RGC transfection and sustained transgene expression, but gene therapy programmes for mitochondrial optic neuropathies caused by dominant $O P A 1$ and recessive WFS 1 mutations are currently in development, which will hopefully lead to early phase clinical trials.

The coming decade will bring together a confluence of major advances in cell-based and genomic editing technologies that hold the potential to revolutionise our approach to the prevention and treatment of human genetic diseases [139]. The ability to reprogram postmitotic somatic cells into induced pluripotent stem cells (iPSCs) has been a major breakthrough and the ability to produce patient-specific neuronal populations, including RGCs, opens up not only the possibility of personalised regenerative medicine, but in the shorter term, highthroughput drug screening on the diseased cells of interest can be actively exploited. Although the RGC layer is easily accessible, multisystem neurological involvement represents a major challenge and another strand of research has focused on the prevention of disease transmission from mother to child. There is an estimated 2300 women of childbearing age in the United Kingdom that harbour pathogenic mtDNA mutations and by using the national fertility rate, about 150 newborn per year would be at high risk of developing severe mitochondrial disease [56]. A pioneering therapeutic approach is to use conventional IVF techniques to transfer the parental nuclear genetic material into a donor egg containing a normal wild-type mtDNA population such that the child's entire genetic make-up will be derived from the biological parents except for the 37 mitochondrial genes. Pronuclear transfer and metaphase II spindle transfer are the two techniques that are currently being refined and further experimental work will hopefully validate the safety of these potentially groundbreaking mitochondrial replacement strategies [43, 67, 127, 128]. Following a wide-ranging public consultation, in February 2015, both Houses of Parliament in the United Kingdom have voted strongly in favour of mitochondrial donation to prevent the maternal transmission of mitochondrial disease (http://www. wellcome.ac.uk/About-us/Policy/Spotlight-issues/Mitochondrial-diseases/, accessed on 28 August 2016). Safety must remain the primary concern at all times and tight regulations must be agreed and implemented at national and international levels to avoid misuse of these promising, but as yet unproven, methods aimed at preventing the maternal transmission of pathogenic mtDNA mutations to the next generation.

\section{Conclusions}

All the causative genes identified so far in patients with inherited optic neuropathies result in mitochondrial dysfunction and it is abundantly clear that RGCs are exquisitely sensitive to even minor disturbances in mitochondrial biogenesis or dynamics, with an innate susceptibility to undergo apoptosis under conditions of heightened cellular stress and elevated ROS levels. It is still difficult to fully unravel the individual contribution of these often overlapping pathophysiological mechanisms but, nevertheless, they do provide a number of targets amenable to therapeutic modulation. The pace of gene discovery will continue to accelerate with the advent of next-generation sequencing technologies, providing not only a confirmed molecular diagnosis to patients and their families, but also important insights into new protein mediators that regular RGC and neuronal survival. The stark reality is that the majority of patients with mitochondrial optic neuropathies are registered legally blind and the translational gap for this group of disorders remains to be bridged. However, all the signs point towards a turning point and the availability of better disease models coupled with innovation in bioimaging, drug discovery and genetic manipulation brings renewed hope that clinicians will soon be 
in a position to better monitor disease progression and improve the visual prognosis of patients with mitochondrial optic neuropathies.

Acknowledgments PYWM is supported by a Clinician Scientist Fellowship Award (G1002570) from the Medical Research Council (UK), and also receives funding from Fight for Sight (UK), the UK National Institute of Health Research (NIHR) as part of the Rare Diseases Translational Research Collaboration, and the NIHR Biomedical Research Centre based at Moorfields Eye Hospital NHS Foundation Trust and UCL Institute of Ophthalmology. MV is funded by Fight for Sight (UK) and the UK National Institute of Health Research (NIHR) as part of the Rare Diseases Translational Research Collaboration. The views expressed are those of the author(s) and not necessarily those of the NHS, the NIHR or the Department of Health. VC is funded by the Italian Ministries of Health and of Research, TelethonItaly, e-RARE and patient-led organisations (IFOND, UMDF, MITOCON, The Poincenot Family, and the Gino Galletti Foundation). CLM receives financial support from the Italian Ministry of Health. We are grateful to Prof. Alfredo Sadun and Dr. Fred Ross-Cisneros (Doheny Eye Institute, UCLA) for the histological slides used in Fig 4, and to Dr. Terence Smith (Cardiff University) for the RGC images used in Fig 5.

\section{Compliance with ethical standards}

Financial disclosures PYWM holds a consultancy agreement with GenSight Biologics. VC holds consultancy agreements with GenSight Biologics, Santhera Pharmaceuticals, Stealth BioTherapeutics and Edison Pharmaceuticals.

Open Access This article is distributed under the terms of the Creative Commons Attribution 4.0 International License (http://creativecommons.org/licenses/by/4.0/), which permits unrestricted use, distribution, and reproduction in any medium, provided you give appropriate credit to the original author(s) and the source, provide a link to the Creative Commons license, and indicate if changes were made.

\section{References}

1. Abrams AJ, Hufnagel RB, Rebelo A, Zanna C, Patel N, Gonzalez MA, Campeanu IJ, Griffin LB, Groenewald S, Strickland $\mathrm{AV}$ et al (2015) Mutations in SLC25A46, encoding a UGO1like protein, cause an optic atrophy spectrum disorder. Nat Genet 47:926-932. doi:10.1038/ng.3354

2. Adams JH, Blackwood W, Wilson J (1966) Further clinical and pathological observations on Leber's optic atrophy. Brain 89:15-26

3. Alavi MV, Bette S, Schimpf S, Schuettauf F, Schraermeyer U, Wehrl HF, Ruttiger L, Beck SC, Tonagel F, Pichler BJ et al (2007) A splice site mutation in the murine Opa1 gene features pathology of autosomal dominant optic atrophy. Brain 130:1029-1042. doi:10.1093/brain/awm005

4. Alavi MV, Fuhrmann N, Nguyen HP, Yu-Wai-Man P, Heiduschka P, Chinnery PF, Wissinger B (2009) Subtle neurological and metabolic abnormalities in an Opa1 mouse model of autosomal dominant optic atrophy. Exp Neurol 220:404-409. doi:10.1016/j.expneurol.2009.09.026

5. Alexander C, Votruba M, Pesch UE, Thiselton DL, Mayer S, Moore A, Rodriguez M, Kellner U, Leo-Kottler B, Auburger $\mathrm{G}$ et al (2000) OPA1, encoding a dynamin-related GTPase, is mutated in autosomal dominant optic atrophy linked to chromosome 3q28. Nat Genet 26:211-215. doi:10.1038/79944

6. Amati-Bonneau P, Guichet A, Olichon A, Chevrollier A, Viala F, Miot S, Ayuso C, Odent S, Arrouet C, Verny C et al (2005) OPA1 R445H mutation in optic atrophy associated with sensorineural deafness. Ann Neurol 58:958-963. doi:10.1002/ ana. 20681

7. Amati-Bonneau $\mathrm{P}$, Valentino ML, Reynier $\mathrm{P}$, Gallardo ME, Bornstein B, Boissiere A, Campos Y, Rivera H, de la Aleja JG, Carroccia R et al (2008) OPA1 mutations induce mitochondrial DNA instability and optic atrophy 'plus' phenotypes. Brain 131:338-351. doi:10.1093/brain/awm298

8. Andrews RM, Griffiths PG, Johnson MA, Turnbull DM (1999) Histochemical localisation of mitochondrial enzyme activity in human optic nerve and retina. Br J Ophthalmol 83:231-235

9. Angebault C, Guichet PO, Talmat-Amar Y, Charif M, Gerber S, Fares-Taie L, Gueguen N, Halloy F, Moore D, Amati-Bonneau $P$ et al (2015) Recessive mutations in RTN4IP1 cause isolated and syndromic optic neuropathies. Am J Hum Genet 97:754760. doi:10.1016/j.ajhg.2015.09.012

10. Anikster Y, Kleta R, Shaag A, Gahl WA, Elpeleg O (2001) Type III 3-methylglutaconic aciduria (optic atrophy plus syndrome, or Costeff optic atrophy syndrome): identification of the OPA3 gene and its founder mutation in Iraqi Jews. Am J Hum Genet 69:1218-1224. doi:10.1086/324651

11. Antonicka H, Ostergaard E, Sasarman F, Weraarpachai W, Wibrand F, Pedersen AM, Rodenburg RJ, van der Knaap MS, Smeitink JA, Chrzanowska-Lightowlers ZM et al (2010) Mutations in C12orf65 in patients with encephalomyopathy and a mitochondrial translation defect. Am J Hum Genet 87:115-122. doi:10.1016/j.ajhg.2010.06.004

12. Bailie M, Votruba M, Griffiths PG, Chinnery PF, Yu-Wai-Man P (2013) Visual and psychological morbidity among patients with autosomal dominant optic atrophy. Acta Ophthalmol 91:e413-e414

13. Baker MR, Fisher KM, Whittaker RG, Griffiths PG, Yu-WaiMan P, Chinnery PF (2011) Subclinical multisystem neurologic disease in "Pure" Opa1 autosomal dominant optic atrophy. Neurology 77:1309-1312. doi:10.1212/WNL.0b013e318230a15a

14. Balducci N, Savini G, Cascavilla ML, La Morgia C, Triolo G, Giglio R, Carbonelli M, Parisi V, Sadun AA, Bandello F et al (2015) Macular nerve fibre and ganglion cell layer changes in acute Leber's hereditary optic neuropathy. Br J Ophthalmol. doi:10.1136/bjophthalmol-2015-307326

15. Barboni P, Carbonelli M, Savini G, Foscarini B, Parisi V, Valentino ML, Carta A, De Negri A, Sadun F, Zeviani M et al (2010) OPA1 mutations associated with dominant optic atrophy influence optic nerve head size. Ophthalmology 117:1547-1553. doi:10.1016/j.ophtha.2009.12.042

16. Barboni P, Carbonelli M, Savini G, Ramos Cdo V, Carta A, Berezovsky A, Salomao SR, Carelli V, Sadun AA (2010) Natural history of Leber's hereditary optic neuropathy: longitudinal analysis of the retinal nerve fiber layer by optical coherence tomography. Ophthalmology 117:623-627. doi:10.1016/j. ophtha.2009.07.026

17. Barboni P, Carelli V, Savini G, Carbonelli M, La Morgia C, Sadun AA (2013) Microcystic macular degeneration from optic neuropathy: not inflammatory, not trans-synaptic degeneration. Brain 136:e239. doi:10.1093/brain/awt014

18. Barboni P, Savini G, Cascavilla ML, Caporali L, Milesi J, Borrelli E, La Morgia C, Valentino ML, Triolo G, Lembo A et al (2014) Early macular retinal ganglion cell loss in dominant optic atrophy: genotype-phenotype correlation. Am J Ophthalmol 158(628-636):e623. doi:10.1016/j.ajo.2014.05.034

19. Barboni P, Savini G, Feuer WJ, Budenz DL, Carbonelli M, Chicani F, Ramos Cdo V, Salomao SR, Negri AD, Parisi V et al 
(2012) Retinal nerve fiber layer thickness variability in Leber hereditary optic neuropathy carriers. Eur J Ophthalmol 22:985991. doi:10.5301/ejo.5000154

20. Barboni P, Savini G, Parisi V, Carbonelli M, La Morgia C, Maresca A, Sadun F, De Negri AM, Carta A, Sadun AA et al (2011) Retinal nerve fiber layer thickness in dominant optic atrophy measurements by optical coherence tomography and correlation with age. Ophthalmology 118:2076-2080. doi:10.1016/j.ophtha.2011.02.027

21. Barboni P, Savini G, Valentino ML, Montagna P, Cortelli P, De Negri AM, Sadun F, Bianchi S, Longanesi L, Zanini M et al (2005) Retinal nerve fiber layer evaluation by optical coherence tomography in Leber's hereditary optic neuropathy. Ophthalmology 112:120-126. doi:10.1016/j.ophtha.2004.06.034

22. Barcella V, Rocca MA, Bianchi-Marzoli S, Milesi J, Melzi L, Falini A, Pierro L, Filippi M (2010) Evidence for retrochiasmatic tissue loss in Leber's hereditary optic neuropathy. Hum Brain Mapp 31:1900-1906. doi:10.1002/hbm.20985

23. Bennett JL, de Seze J, Lana-Peixoto M, Palace J, Waldman A, Schippling S, Tenembaum S, Banwell B, Greenberg B, Levy M et al (2015) Neuromyelitis optica and multiple sclerosis: seeing differences through optical coherence tomography. Mult Scler 21:678-688. doi:10.1177/1352458514567216

24. Blakely EL, de Silva R, King A, Schwarzer V, Harrower T, Dawidek G, Turnbull DM, Taylor RW (2005) LHON/MELAS overlap syndrome associated with a mitochondrial MTND1 gene mutation. Eur J Hum Genet 13:623-627

25. Bonifert T, Karle KN, Tonagel F, Batra M, Wilhelm C, Theurer Y, Schoenfeld C, Kluba T, Kamenisch Y, Carelli V et al (2014) Pure and syndromic optic atrophy explained by deep intronic OPA1 mutations and an intralocus modifier. Brain 137:21642177. doi:10.1093/brain/awu165

26. Bonneau D, Colin E, Oca F, Ferre M, Chevrollier A, Gueguen N, Desquiret-Dumas V, N'Guyen S, Barth M, Zanlonghi X et al (2014) Early-onset Behr syndrome due to compound heterozygous mutations in OPA1. Brain 137:e301. doi:10.1093/brain/ awu184

27. Bristow EA, Griffiths PG, Andrews RM, Johnson MA, Turnbull DM (2002) The distribution of mitochondrial activity in relation to optic nerve structure. Arch Ophthalmol 120:791-796

28. Burte F, Carelli V, Chinnery PF, Yu-Wai-Man P (2015) Disturbed mitochondrial dynamics and neurodegenerative disorders. Nat Rev Neurol 11:11-24. doi:10.1038/ nrneurol.2014.228

29. Carbonelli M, La Morgia C, Savini G, Cascavilla ML, Borrelli E, Chicani F, do VFRC, Salomao SR, Parisi V, Sebag J et al (2015) Macular microcysts in mitochondrial optic neuropathies: prevalence and retinal layer thickness measurements. PLoS One 10:e0127906. doi:10.1371/journal.pone.0127906

30. Carelli V, Bellan M (2008) Myelin, mitochondria, and autoimmunity-What's the connection? Neurology 70:1075-1076

31. Carelli V, Chan DC (2014) Mitochondrial DNA: impacting central and peripheral nervous systems. Neuron 84:1126-1142. doi:10.1016/j.neuron.2014.11.022

32. Carelli V, Ghelli A, Baracca A, Zanna C, Sgarbi G, Solaini G, Lenaz G, Rugolo M, Martinuzzi A (2004) Severe defect of complex I-dependent ATP synthesis shapes the mitochondriadriven path of apoptotic cell death in Leber's hereditary optic neuropathy. Biochimica Et Biophysica Acta-Bioenerg 1657:70

33. Carelli V, La Morgia C, Valentino ML, Rizzo G, Carbonelli M, De Negri AM, Sadun F, Carta A, Guerriero S, Simonelli F et al (2011) Idebenone treatment in Leber's hereditary optic neuropathy. Brain 134:e188. doi:10.1093/brain/awr180

34. Carelli V, Musumeci O, Caporali L, Zanna C, La Morgia C, Del Dotto V, Porcelli AM, Rugolo M, Valentino ML, Iommarini L et al (2015) Syndromic parkinsonism and dementia associated with OPA1 missense mutations. Ann Neurol 78:21-38. doi:10.1002/ana.24410

35. Carelli V, Ross-Cisneros FN, Sadun AA (2004) Mitochondrial dysfunction as a cause of optic neuropathies. Prog Retinal Eye Res 23:53-89

36. Carelli V, Ross-Cisneros FN, Sadun AA (2002) Optic nerve degeneration and mitochondrial dysfunction: genetic and acquired optic neuropathies. Neurochem Int 40:573-584

37. Carelli V, Sabatelli M, Carrozzo R, Rizza T, Schimpf S, Wissinger B, Zanna C, Rugolo M, La Morgia C, Caporali L et al (2015) 'Behr syndrome' with OPA1 compound heterozygote mutations. Brain 138:e321. doi:10.1093/brain/awu234

38. Carelli V, Valentino ML, Liguori R, Meletti S, Vetrugno R, Provini F, Mancardi GL, Bandini F, Baruzzi A, Montagna P (2001) Leber's hereditary optic neuropathy (LHON/11778) with myoclonus: report of two cases. J Neurol Neurosurg Psychiatry 71:813-816

39. Charif M, Roubertie A, Salime S, Mamouni S, Goizet C, Hamel CP, Lenaers G (2015) A novel mutation of AFG3L2 might cause dominant optic atrophy in patients with mild intellectual disability. Front Genet 6:311. doi:10.3389/ fgene.2015.00311

40. Chen L, Liu T, Tran A, Lu X, Tomilov AA, Davies V, Cortopassi G, Chiamvimonvat N, Bers DM, Votruba M et al (2012) OPA1 mutation and late-onset cardiomyopathy: mitochondrial dysfunction and mtDNA instability. J Am Heart Assoc 1:e003012. doi:10.1161/JAHA.112.003012

41. Cohn AC, Toomes C, Hewitt AW, Kearns LS, Inglehearn CF, Craig JE, Mackey DA (2008) The natural history of OPA1related autosomal dominant optic atrophy. $\mathrm{Br} \mathrm{J}$ Ophthalmol 92:1333-1336. doi:10.1136/bjo.2007.134726

42. Cohn AC, Toomes C, Potter C, Towns KV, Hewitt AW, Inglehearn CF, Craig JE, Mackey DA (2007) Autosomal dominant optic atrophy: penetrance and expressivity in patients with OPA1 mutations. Am J Ophthalmol 143:656-662. doi:10.1016/j.ajo.2006.12.038

43. Craven L, Tuppen HA, Greggains GD, Harbottle SJ, Murphy JL, Cree LM, Murdoch AP, Chinnery PF, Taylor RW, Lightowlers RN et al (2010) Pronuclear transfer in human embryos to prevent transmission of mitochondrial DNA disease. Nature 465:82-85

44. D'Aguanno S, Barassi A, Lupisella S, d'eril GM, Del Boccio P, Pieragostino D, Pallotti F, Carelli V, Valentino ML, Liguori R et al (2008) Differential cerebro spinal fluid proteome investigation of Leber hereditary optic neuropathy (LHON) and multiple sclerosis. J Neuroimmunol 193:156-160

45. Davey KM, Parboosingh JS, McLeod DR, Chan A, Casey R, Ferreira P, Snyder FF, Bridge PJ, Bernier FP (2006) Mutation of DNAJC19, a human homologue of yeast inner mitochondrial membrane co-chaperones, causes DCMA syndrome, a novel autosomal recessive Barth syndrome-like condition. J Med Genet 43:385-393. doi:10.1136/jmg.2005.036657

46. Davies VJ, Hollins AJ, Piechota MJ, Yip W, Davies JR, White KE, Nicols PP, Boulton ME, Votruba M (2007) Opa1 deficiency in a mouse model of autosomal dominant optic atrophy impairs mitochondrial morphology, optic nerve structure and visual function. Hum Mol Genet 16:1307-1318. doi:10.1093/hmg/ ddm079

47. Delettre C, Lenaers G, Griffoin JM, Gigarel N, Lorenzo C, Belenguer P, Pelloquin L, Grosgeorge J, Turc-Carel C, Perret E et al (2000) Nuclear gene OPA1, encoding a mitochondrial dynamin-related protein, is mutated in dominant optic atrophy. Nat Genet 26:207-210. doi:10.1038/79936

48. Elachouri G, Vidoni S, Zanna C, Pattyn A, Boukhaddaoui H, Gaget K, Yu-Wai-Man P, Gasparre G, Sarzi E, Delettre C et al (2011) OPA1 links human mitochondrial genome maintenance 
to mtDNA replication and distribution. Genome Res 21:12-20. doi:10.1101/gr.108696.110

49. Ellouze S, Augustin S, Bouaita A, Bonnet C, Simonutti M, Forster V, Picaud S, Sahel J-A, Corral-Debrinski M (2008) Optimized allotopic expression of the human mitochondrial ND4 prevents blindness in a rat model of mitochondrial dysfunction. Am J Hum Genet 83:373-387

50. Ferre M, Bonneau D, Milea D, Chevrollier A, Verny C, Dollfus H, Ayuso C, Defoort S, Vignal C, Zanlonghi X et al (2009) Molecular screening of 980 cases of suspected hereditary optic neuropathy with a report on 77 novel OPA1 mutations. Hum Mutat 30:E692-E705

51. Fortuna F, Barboni P, Liguori R, Valentino ML, Savini G, Gellera C, Mariotti C, Rizzo G, Tonon C, Manners D et al (2009) Visual system involvement in patients with Friedreich's ataxia. Brain 132:116-123. doi:10.1093/brain/awn269

52. Fraser JA, Biousse V, Newman NJ (2010) The neuro-ophthalmology of mitochondrial disease. Surv Ophthalmol 55:299-334

53. Fuhrmann N, Alavi MV, Bitoun P, Woernle S, Auburger G, Leo-Kottler B, Yu-Wai-Man P, Chinnery P, Wissinger B (2009) Genomic rearrangements in OPA1 are frequent in patients with autosomal dominant optic atrophy. J Med Genet 46:136-144. doi:10.1136/jmg.2008.062570

54. Gelfand JM, Cree BA, Nolan R, Arnow S, Green AJ (2013) Microcystic inner nuclear layer abnormalities and neuromyelitis optica. JAMA Neurol 70:629-633. doi:10.1001/ jamaneurol.2013.1832

55. Giordano C, Montopoli M, Perli E, Orlandi M, Fantin M, RossCisneros FN, Caparrotta L, Martinuzzi A, Ragazzi E, Ghelli A et al (2011) Oestrogens ameliorate mitochondrial dysfunction in Leber's hereditary optic neuropathy. Brain 134:220-234

56. Gorman GS, Grady JP, Ng Y, Schaefer AM, McNally RJ, Chinnery PF, Yu-Wai-Man P, Herbert M, Taylor RW, McFarland $\mathrm{R}$ et al (2015) Mitochondrial donation-how many women could benefit? N Engl J Med 372:885-887. doi:10.1056/ NEJMc1500960

57. Gorman GS, Pfeffer G, Griffin H, Blakely EL, KurzawaAkanbi M, Gabriel J, Sitarz K, Roberts M, Schoser B, Pyle A et al (2015) Clonal expansion of secondary mitochondrial DNA deletions associated with spinocerebellar ataxia type 28. JAMA Neurol 72:106-111. doi:10.1001/jamaneurol.2014.1753

58. Gorman GS, Schaefer AM, Ng Y, Gomez N, Blakely EL, Alston CL, Feeney C, Horvath R, Yu-Wai-Man P, Chinnery PF et al (2015) Prevalence of nuclear and mitochondrial DNA mutations related to adult mitochondrial disease. Ann Neurol 77:753-759. doi:10.1002/ana.24362

59. Greaves LC, Yu-Wai-Man P, Blakely EL, Krishnan KJ, Beadle NE, Kerin J, Barron MJ, Griffiths PG, Dickinson AJ, Turnbull DM et al (2010) Mitochondrial DNA defects and selective extraocular muscle involvement in CPEO. Invest Ophthalmol Vis Sci 51:3340-3346. doi:10.1167/iovs.09-4659

60. Gueven N, Faldu D (2013) Idebenone treatment in Leber's hereditary optic neuropathy: rationale and efficacy. Exp Opin Orphan Drugs 1:331-339

61. Guy J, Qi XP, Pallotti F, Schon EA, Manfredi G, Carelli V, Martinuzzi A, Hauswirth WW, Lewin AS (2002) Rescue of a mitochondrial deficiency causing Leber hereditary optic neuropathy. Ann Neurol 52:534-542

62. Hanein S, Perrault I, Roche O, Gerber S, Khadom N, Rio M, Boddaert N, Jean-Pierre M, Brahimi N, Serre V et al (2009) TMEM126A, encoding a mitochondrial protein, is mutated in autosomal-recessive nonsyndromic optic atrophy. Am J Hum Genet 84:493-498. doi:10.1016/j.ajhg.2009.03.003

63. Harding AE, Sweeney MG, Miller DH, Mumford CJ, Kellarwood H, Menard D, McDonald WI, Compston DAS (1992) Occurrence of a multiple sclerosis-like illness in women who have a Lebers hereditary optic neuropathy mitochondrial-DNA mutation. Brain 115:979-989

64. Heidary G, Calderwood L, Cox GF, Robson CD, Teot LA, Mullon J, Anselm I (2014) Optic atrophy and a Leigh-like syndrome due to mutations in the c12orf65 gene: report of a novel mutation and review of the literature. J Neuroophthalmol 34:39-43. doi:10.1097/WNO.0000000000000076

65. Hudson G, Amati-Bonneau P, Blakely EL, Stewart JD, He L, Schaefer AM, Griffiths PG, Ahlqvist K, Suomalainen A, Reynier P et al (2008) Mutation of OPA1 causes dominant optic atrophy with external ophthalmoplegia, ataxia, deafness and multiple mitochondrial DNA deletions: a novel disorder of mtDNA maintenance. Brain 131:329-337. doi:10.1093/brain/ awm 272

66. Hudson G, Keers S, Man PYW, Griffiths P, Huoponen K, Savontaus ML, Nikoskelainen E, Zeviani M, Carrara F, Horvath $\mathrm{R}$ et al (2005) Identification of an X-chromosomal locus and haplotype modulating the phenotype of a mitochondrial DNA disorder. Am J Hum Genet 77:1086-1091

67. Hyslop LA, Blakeley P, Craven L, Richardson J, Fogarty NME, Fragouli E, Lamb M, Wamaitha SE, Prathalingam N, Zhang Q et al (2016) Towards clinical application of pronuclear transfer to prevent mitochondrial DNA disease. Nature 534:383-386. doi:10.1038/nature183030

68. Jacob A, Panicker J, Lythgoe D, Elsone L, Mutch K, Wilson M, Das K, Boggild M (2013) The epidemiology of neuromyelitis optica amongst adults in the Merseyside county of United Kingdom. J Neurol 260:2134-2137. doi:10.1007/ s00415-013-6926-y

69. Janer A, Prudent J, Paupe V, Fahiminiya S, Majewski J, Sgarioto N, Des Rosiers C, Forest A, Lin ZY, Gingras AC et al (2016) SLC25A46 is required for mitochondrial lipid homeostasis and cristae maintenance and is responsible for Leigh syndrome. EMBO Mol Med. doi:10.15252/emmm.201506159

70. Jin H, May M, Tranebjaerg L, Kendall E, Fontan G, Jackson J, Subramony SH, Arena F, Lubs H, Smith S et al (1996) A novel $\mathrm{X}$-linked gene, DDP, shows mutations in families with deafness (DFN-1), dystonia, mental deficiency and blindness. Nat Genet 14:177-180. doi:10.1038/ng1096-177

71. Johnson BM, Miao M, Sadun AA (1987) Age-related decline of human optic-nerve axon populations. Age 10:5-9. doi:10.1007/ BF02431765

72. Johnston PB, Gaster RN, Smith VC, Tripathi RC (1979) A clinicopathologic study of autosomal dominant optic atrophy. Am J Ophthalmol 88:868-875

73. Kerrison JB, Howell N, Miller NR, Hirst L, Green WR (1995) Leber hereditary optic neuropathy. Electron microscopy and molecular genetic analysis of a case. Ophthalmology 102:1509-1516

74. Kirkman MA, Korsten A, Leonhardt M, Dimitriadis K, De Coo IF, Klopstock T, Griffiths PG, Hudson G, Chinnery PF, Yu-WaiMan P (2009) Quality of life in patients with leber hereditary optic neuropathy. Invest Ophthalmol Vis Sci 50:3112-3115. doi:10.1167/iovs.08-3166

75. Kirkman MA, Yu-Wai-Man P, Korsten A, Leonhardt M, Dimitriadis K, De Coo IF, Klopstock T, Chinnery PF (2009) Geneenvironment interactions in Leber hereditary optic neuropathy. Brain 132:2317-2326

76. Kjer P (1959) Infantile optic atrophy with dominant mode of inheritance: a clinical and genetic study of 19 Danish families. Acta Ophthalmol Suppl 164:1-147

77. Kjer P, Jensen OA, Klinken L (1983) Histopathology of eye, optic nerve and brain in a case of dominant optic atrophy. Acta Ophthalmol (Copenh) 61:300-312

78. Klebe S, Depienne C, Gerber S, Challe G, Anheim M, Charles P, Fedirko E, Lejeune E, Cottineau J, Brusco A et al (2012) 
Spastic paraplegia gene 7 in patients with spasticity and/or optic neuropathy. Brain 135:2980-2993. doi:10.1093/brain/aws240

79. Klopstock T, Metz G, Yu-Wai-Man P, Buchner B, Gallenmuller C, Bailie M, Nwali N, Griffiths PG, von Livonius B, Reznicek L et al (2013) Persistence of the treatment effect of idebenone in Leber's hereditary optic neuropathy. Brain 136:e230. doi:10.1093/brain/aws279

80. Klopstock T, Yu-Wai-Man P, Dimitriadis K, Rouleau J, Heck S, Bailie M, Atawan A, Chattopadhyay S, Schubert M, Garip A et al (2011) A randomized placebo-controlled trial of idebenone in Leber's hereditary optic neuropathy. Brain 134:2677-2686

81. Kovacs GG, Hoftberger R, Horvath R, Barsi P, Komoly S, Lassmann H, Budka H, Jakab G (2005) Neuropathology of white matter disease in Leber's hereditary optic neuropathy. Brain 128:35-41

82. La Morgia C, Ross-Cisneros FN, Sadun AA, Hannibal J, Munarini A, Mantovani V, Barboni P, Cantalupo G, Tozer KR, Sancisi E et al (2010) Melanopsin retinal ganglion cells are resistant to neurodegeneration in mitochondrial optic neuropathies. Brain 133:2426-2438. doi:10.1093/brain/awq155

83. Levin LA (2015) Superoxide generation explains common features of optic neuropathies associated with cecocentral scotomas. J Neuroophthalmol 35:152-160. doi:10.1097/ WNO.0000000000000250

84. Lin CS, Sharpley MS, Fan W, Waymire KG, Sadun AA, Carelli V, Ross-Cisneros FN, Baciu P, Sung E, McManus MJ et al (2012) Mouse mtDNA mutant model of Leber hereditary optic neuropathy. Proc Natl Acad Sci USA 109:20065-20070. doi:10.1073/pnas.1217113109

85. Mahad D, Ziabreva I, Lassmann H, Turnbull D (2008) Mitochondrial defects in acute multiple sclerosis lesions. Brain 131:1722-1735

86. Majander A, Bitner-Glindzicz M, Chan CM, Duncan HJ, Chinnery PF, Subash M, Keane PA, Webster AR, Moore AT, Michaelides $M$ et al (2016) Lamination of the outer plexiform layer in optic atrophy caused by dominant WFS1 mutations. Ophthalmology 123:1624-1626

87. Man PY, Griffiths PG, Brown DT, Howell N, Turnbull DM, Chinnery PF (2003) The epidemiology of Leber hereditary optic neuropathy in the North East of England. Am J Hum Genet 72:333-339. doi:10.1086/346066

88. Man PYW, Howell N, Mackey DA, Norby S, Rosenberg T, Turnbull DM, Chinnery PF (2004) Mitochondrial DNA haplogroup distribution within Leber hereditary optic neuropathy pedigrees. J Med Genet 41:e41

89. Manners DN, Rizzo G, La Morgia C, Tonon C, Testa C, Barboni P, Malucelli E, Valentino ML, Caporali L, Strobbe D et al (2015) Diffusion tensor imaging mapping of brain white matter pathology in mitochondrial optic neuropathies. AJNR Am J Neuroradiol 36:1259-1265. doi:10.3174/ajnr.A4272

90. Marelli C, Amati-Bonneau P, Reynier P, Layet V, Layet A, Stevanin G, Brissaud E, Bonneau D, Durr A, Brice A (2011) Heterozygous OPA1 mutations in Behr syndrome. Brain 134: e169; author reply e170 Doi 10.1093/brain/awq306

91. McClelland CM, Van Stavern GP, Tselis AC (2011) Leber hereditary optic neuropathy mimicking neuromyelitis optica. J Neuroophthalmol 31:265-268. doi:10.1097/ WNO.0b013e318225247b

92. McFarland R, Chinnery PF, Blakely EL, Schaefer AM, Morris AAM, Foster SM, Tuppen HAL, Ramesh V, Dorman PJ, Turnbull $\mathrm{M}$ et al (2007) Homoplasmy, heteroplasmy, and mitochondrial dystonia. Neurology 69:911-916

93. Metodiev MD, Gerber S, Hubert L, Delahodde A, Chretien D, Gerard X, Amati-Bonneau P, Giacomotto MC, Boddaert N, Kaminska A et al (2014) Mutations in the tricarboxylic acid cycle enzyme, aconitase 2, cause either isolated or syndromic optic neuropathy with encephalopathy and cerebellar atrophy. J Med Genet 51:834-838. doi:10.1136/ jmedgenet-2014-102532

94. Milesi J, Rocca MA, Bianchi-Marzoli S, Petrolini M, Pagani E, Falini A, Comi G, Filippi M (2012) Patterns of white matter diffusivity abnormalities in Leber's hereditary optic neuropathy: a tract-based spatial statistics study. J Neurol 259:1801-1807. doi:10.1007/s00415-011-6406-1

95. Misu T, Fujihara K, Kakita A, Konno H, Nakamura M, Watanabe S, Takahashi T, Nakashima I, Takahashi H, Itoyama Y (2007) Loss of aquaporin 4 in lesions of neuromyelitis optica: distinction from multiple sclerosis. Brain 130:1224-1234

96. Moura AL, Nagy BV, La Morgia C, Barboni P, Oliveira AG, Salomao SR, Berezovsky A, de Moraes-Filho MN, Chicani CF, Belfort R Jr (2013) The pupil light reflex in Leber's hereditary optic neuropathy: evidence for preservation of melanopsin-expressing retinal ganglion cells. Invest Ophthalmol Vis Sci 54:4471-4477. doi:10.1167/iovs.12-11137

97. Newman NJ, Lott MT, Wallace DC (1991) The clinical characteristics of pedigrees of Lebers hereditary optic neuropathy with the 11778 mutation. Am J Ophthalmol 111:750-762

98. Nikoskelainen EK, Marttila RJ, Huoponen K, Juvonen V, Lamminen T, Sonninen P, Savontaus ML (1995) Lebers plus-neurological abnormalities in patients with Lebers hereditary optic neuropathy. J Neurol Neurosurg Psychiatry 59:160-164

99. Ostojic J, Jancic J, Kozic D, Semnic R, Koprivsek K, Prvulovic M, Kostic V (2009) Brain white matter 1 H MRS in Leber optic neuropathy mutation carriers. Acta Neurol Belg 109:305-309

100. Palace J (2009) Multiple sclerosis associated with Leber's hereditary optic neuropathy. J Neurol Sci 286:24-27

101. Pan BX, Ross-Cisneros FN, Carelli V, Rue KS, Salomao SR, Moraes-Filho MN, Moraes MN, Berezovsky A, Belfort R Jr, Sadun AA (2012) Mathematically modeling the involvement of axons in Leber's hereditary optic neuropathy. Invest Ophthalmol Vis Sci 53:7608-7617. doi:10.1167/iovs.12-10452

102. Payne BA, Wilson IJ, Yu-Wai-Man P, Coxhead J, Deehan D, Horvath R, Taylor RW, Samuels DC, Santibanez-Koref M, Chinnery PF (2013) Universal heteroplasmy of human mitochondrial DNA. Hum Mol Genet 22:384-390. doi:10.1093/ hmg/dds 435

103. Pereira WL, Reiche EM, Kallaur AP, Kaimen-Maciel DR (2015) Epidemiological, clinical, and immunological characteristics of neuromyelitis optica: a review. J Neurol Sci 355:7-17. doi:10.1016/j.jns.2015.05.034

104. Pfeffer G, Burke A, Yu-Wai-Man P, Compston DA, Chinnery PF (2013) Clinical features of MS associated with Leber hereditary optic neuropathy mtDNA mutations. Neurology 81:2073-2081. doi:10.1212/01.wnl.0000437308.22603.43

105. Pfeffer G, Gorman GS, Griffin H, Kurzawa-Akanbi M, Blakely EL, Wilson I, Sitarz K, Moore D, Murphy JL, Alston CL et al (2014) Mutations in the SPG7 gene cause chronic progressive external ophthalmoplegia through disordered mitochondrial DNA maintenance. Brain 137:1323-1336. doi:10.1093/brain/ awu060

106. Pfeffer G, Horvath R, Klopstock T, Mootha VK, Suomalainen A, Koene S, Hirano M, Zeviani M, Bindoff LA, Yu-Wai-Man P et al (2013) New treatments for mitochondrial disease-no time to drop our standards. Nat Rev Neurol 9:474-481

107. Pyle A, Ramesh V, Bartsakoulia M, Boczonadi V, Gomez-Duran A, Herczegfalvi A, Blakely EL, Smertenko T, Duff J, Eglon G et al (2014) Behr's syndrome is typically associated with disturbed mitochondrial translation and mutations in the gene. $\mathrm{J}$ Neuromuscul Dis 1:55-63. doi:10.3233/jnd-140003

108. Qi X, Sun L, Hauswirth WW, Lewin AS, Guy J (2007) Use of mitochondrial antioxidant defenses for rescue of cells with a 
Leber hereditary optic neuropathy-causing mutation. Arch Ophthalmol 125:268-272. doi:10.1001/archopht.125.2.268

109. Renaldo F, Amati-Bonneau P, Slama A, Romana C, Forin V, Doummar D, Barnerias C, Bursztyn J, Mayer M, Khouri N et al (2012) MFN2, a new gene responsible for mitochondrial DNA depletion. Brain 135:e223. doi:10.1093/brain/aws111

110. Rendtorff ND, Lodahl M, Boulahbel H, Johansen IR, Pandya A, Welch KO, Norris VW, Arnos KS, Bitner-Glindzicz M, Emery SB et al (2011) Identification of p. A684 V missense mutation in the WFS1 gene as a frequent cause of autosomal dominant optic atrophy and hearing impairment. Am J Med Genet A 155A:1298-1313. doi:10.1002/ajmg.a.33970

111. Reynier P, Amati-Bonneau P, Verny C, Olichon A, Simard G, Guichet A, Bonnemains C, Malecaze F, Malinge MC, Pelletier JB et al (2004) OPA3 gene mutations responsible for autosomal dominant optic atrophy and cataract. J Med Genet 41:e110. doi:10.1136/jmg.2003.016576

112. Rocca MA, Bianchi-Marzoli S, Messina R, Cascavilla ML, Zeviani M, Lamperti C, Milesi J, Carta A, Cammarata G, Leocani L et al (2015) Distributed abnormalities of brain white matter architecture in patients with dominant optic atrophy and OPA1 mutations. J Neurol 262:1216-1227. doi:10.1007/ s00415-015-7696-5

113. Roemer SF, Parisi JE, Lennon VA, Benarroch EE, Lassmann H, Bruck W, Mandler RN, Weinshenker BG, Pittock SJ, Wingerchuk DM et al (2007) Pattern-specific loss of aquaporin-4 immunoreactivity distinguishes neuromyelitis optica from multiple sclerosis. Brain 130:1194-1205

114. Roubertie A, Leboucq N, Picot MC, Nogue E, Brunel H, Le Bars E, Manes G, Prouteau CA, Blanchet C, Mondain M et al (2015) Neuroradiological findings expand the phenotype of OPA1-related mitochondrial dysfunction. J Neurol Sci 349:154-160. doi:10.1016/j.jns.2015.01.008

115. Rouzier C, Bannwarth S, Chaussenot A, Chevrollier A, Verschueren A, Bonello-Palot N, Fragaki K, Cano A, Pouget J, Pellissier JF et al (2012) The MFN2 gene is responsible for mitochondrial DNA instability and optic atrophy 'plus' phenotype. Brain 135:23-34. doi:10.1093/brain/awr323

116. Saadati HG, Hsu HY, Heller KB, Sadun AA (1998) A histopathologic and morphometric differentiation of nerves in optic nerve hypoplasia and leber hereditary optic neuropathy. Arch Ophthalmol 116:911-916

117. Sadun AA, Chicani CF, Ross-Cisneros FN, Barboni P, Thoolen M, Shrader WD, Kubis K, Carelli V, Miller G (2012) Effect of EPI-743 on the clinical course of the mitochondrial disease Leber hereditary optic neuropathy. Arch Neurol 69:331-338. doi:10.1001/archneurol.2011.2972

118. Sadun AA, Win PH, Ross-Cisneros FN, Walker SO, Carelli V (2000) Leber's hereditary optic neuropathy differentially affects smaller axons in the optic nerve. Trans Am Ophthalmol Soc 98:223-232 (discussion 232-225)

119. Sadun AAKY, Wurdeman AE, Dao J, Heller K, Sherman J (1994) Morphological findings in the visual system in a case of Leber's hereditary optic neuropathy. Clin Neurosci 2:165-172

120. Sarzi E, Angebault C, Seveno M, Gueguen N, Chaix B, Bielicki G, Boddaert N, Mausset-Bonnefont AL, Cazevieille C, Rigau V et al (2012) The human OPA1delTTAG mutation induces premature age-related systemic neurodegeneration in mouse. Brain 135:3599-3613. doi:10.1093/brain/aws303

121. Savini G, Barboni P, Valentino ML, Montagna P, Cortelli P, De Negri AM, Sadun F, Bianchi S, Longanesi L, Zanini M et al (2005) Retinal nerve fiber layer evaluation by optical coherence tomography in unaffected carriers with Leber's hereditary optic neuropathy mutations. Ophthalmology 112:127-131. doi:10.1016/j.ophtha.2004.09.033
122. Shiraishi W, Hayashi S, Kamada T, Isobe N, Yamasaki R, Murai H, Ohyagi Y, Kira J (2014) A case of neuromyelitis optica harboring both anti-aquaporin-4 antibodies and a pathogenic mitochondrial DNA mutation for Leber's hereditary optic neuropathy. Mult Scler 20:258-260. doi:10.1177/1352458513513057

123. Spiegel R, Saada A, Flannery PJ, Burte F, Soiferman D, Khayat M, Eisner V, Vladovski E, Taylor RW, Bindoff LA et al (2016) Fatal infantile mitochondrial encephalomyopathy, hypertrophic cardiomyopathy and optic atrophy associated with a homozygous OPA1 mutation. J Med Genet 53:127-131. doi:10.1136/ jmedgenet-2015-103361

124. Spruijt L, Smeets HJ, Hendrickx A, Bettink-Remeijer MW, Maat-Kievit A, Schoonderwoerd KC, Sluiter W, de Coo IF, Hintzen RQ (2007) A MELAS-associated ND1 mutation causing Leber hereditary optic neuropathy and spastic dystonia. Arch Neurol 64:890-893

125. Stewart JD, Hudson G, Yu-Wai-Man P, Blakeley EL, He L, Horvath R, Maddison P, Wright A, Griffiths PG, Turnbull DM et al (2008) OPA1 in multiple mitochondrial DNA deletion disorders. Neurology 71:1829-1831. doi:10.1212/01. wnl.0000335931.54095.0a

126. Strom TM, Hortnagel K, Hofmann S, Gekeler F, Scharfe C, Rabl W, Gerbitz KD, Meitinger T (1998) Diabetes insipidus, diabetes mellitus, optic atrophy and deafness (DIDMOAD) caused by mutations in a novel gene (wolframin) coding for a predicted transmembrane protein. Hum Mol Genet 7:20212028. doi: $10.1093 / \mathrm{hmg} / 7.13 .2021$

127. Tachibana M, Amato P, Sparman M, Woodward J, Sanchis DM, Ma H, Gutierrez NM, Tippner-Hedges R, Kang E, Lee HS et al (2013) Towards germline gene therapy of inherited mitochondrial diseases. Nature 493:627-631

128. Tachibana M, Sparman M, Sritanaudomchai H, Ma H, Clepper L, Woodward J, Li Y, Ramsey C, Kolotushkina O, Mitalipov S (2009) Mitochondrial gene replacement in primate offspring and embryonic stem cells. Nature 461:367-372

129. Tatsuta T, Langer T (2008) Quality control of mitochondria: protection against neurodegeneration and ageing. EMBO J 27:306-314. doi:10.1038/sj.emboj.7601972

130. Tranebjaerg L, Jensen PK, Van Ghelue M, Vnencak-Jones CL, Sund S, Elgjo K, Jakobsen J, Lindal S, Warburg M, Fuglsang-Frederiksen A et al (2001) Neuronal cell death in the visual cortex is a prominent feature of the $\mathrm{X}$-linked recessive mitochondrial deafness-dystonia syndrome caused by mutations in the TIMM8a gene. Ophthalmic Genet 22:207-223

131. Tun AW, Chaiyarit S, Kaewsutthi S, Katanyoo W, Chuenkongkaew W, Kuwano M, Tomonaga T, Peerapittayamongkol C, Thongboonkerd V, Lertrit P (2014) Profiling the mitochondrial proteome of Leber's hereditary optic neuropathy (LHON) in Thailand: down-regulation of bioenergetics and mitochondrial protein quality control pathways in fibroblasts with the $11778 \mathrm{G}>\mathrm{a}$ mutation. PLoS One 9:e106779. doi:10.1371/journal.pone.0106779

132. Turnbull HE, Lax NZ, Diodato D, Ansorge O, Turnbull DM (2010) The mitochondrial brain: from mitochondrial genome to neurodegeneration. Biochimica Et Biophysica Acta-Molecular Basis Dis 1802:111-121. doi:10.1016/j. bbadis.2009.07.010

133. Verny C, Loiseau D, Scherer C, Lejeune P, Chevrollier A, Gueguen N, Guillet V, Dubas F, Reynier P, Amati-Bonneau P et al (2008) Multiple sclerosis-like disorder in OPA1-related autosomal dominant optic atrophy. Neurology 70:1152-1153

134. Wallace DC, Singh G, Lott MT, Hodge JA, Schurr TG, Lezza AM, Elsas LJ 2nd, Nikoskelainen EK (1988) Mitochondrial DNA mutation associated with Leber's hereditary optic neuropathy. Science 242:1427-1430 
135. Waterham HR, Koster J, van Roermund CW, Mooyer PA, Wanders RJ, Leonard JV (2007) A lethal defect of mitochondrial and peroxisomal fission. N Engl J Med 356:1736-1741. doi:10.1056/NEJMoa064436

136. Wiley SE, Andreyev AY, Divakaruni AS, Karisch R, Perkins G, Wall EA, van der Geer P, Chen YF, Tsai TF, Simon MI et al (2013) Wolfram syndrome protein, Miner1, regulates sulphydryl redox status, the unfolded protein response, and $\mathrm{Ca} 2$ + homeostasis. EMBO Mol Med 5:904-918. doi:10.1002/ emmm.201201429

137. Williams PA, Piechota M, von Ruhland C, Taylor E, Morgan JE, Votruba M (2012) Opa1 is essential for retinal ganglion cell synaptic architecture and connectivity. Brain 135:493-505. doi:10.1093/brain/awr330

138. Wingerchuk DM, Lennon VA, Lucchinetti CF, Pittock S, Weinshenker BG (2007) The spectrum of neuromyelitis optica. Lancet Neurol 6:805-815

139. Yu-Wai-Man P (2016) Genetic manipulation for inherited neurodegenerative diseases: myth or reality? $\mathrm{Br} \mathrm{J}$ Ophthalmol. doi:10.1136/bjophthalmol-2015-308329

140. Yu-Wai-Man P, Bailie M, Atawan A, Chinnery PF, Griffiths PG (2011) Pattern of retinal ganglion cell loss in dominant optic atrophy due to OPA1 mutations. Eye (Lond) 25:596-602. doi:10.1038/eye.2011.2

141. Yu-Wai-Man P, Chinnery PF (2012) Dysfunctional mitochondrial maintenance: what breaks the circle of life? Brain 135:911. doi:10.1093/brain/awr352

142. Yu-Wai-Man P, Griffiths PG, Burke A, Sellar PW, Clarke MP, Gnanaraj L, Ah-Kine D, Hudson G, Czermin B, Taylor RW et al (2010) The prevalence and natural history of dominant optic atrophy due to OPA1 mutations. Ophthalmology 117:15381546. doi:10.1016/j.ophtha.2009.12.038

143. Yu-Wai-Man P, Griffiths PG, Chinnery PF (2011) Mitochondrial optic neuropathies-Disease mechanisms and therapeutic strategies. Progress Retinal Eye Res 30:81-114
144. Yu-Wai-Man P, Griffiths PG, Gorman GS, Lourenco CM, Wright AF, Auer-Grumbach M, Toscano A, Musumeci O, Valentino ML, Caporali L et al (2010) Multi-system neurological disease is common in patients with OPA1 mutations. Brain 133:771-786. doi:10.1093/brain/awq007

145. Yu-Wai-Man P, Lai-Cheong J, Borthwick GM, He L, Taylor GA, Greaves LC, Taylor RW, Griffiths PG, Turnbull DM (2010) Somatic mitochondrial DNA deletions accumulate to high levels in aging human extraocular muscles. Invest Ophthalmol Vis Sci 51:3347-3353. doi:10.1167/iovs.09-4660

146. Yu-Wai-Man P, Sitarz KS, Samuels DC, Griffiths PG, Reeve AK, Bindoff LA, Horvath R, Chinnery PF (2010) OPA1 mutations cause cytochrome $\mathrm{c}$ oxidase deficiency due to loss of wild-type mtDNA molecules. Hum Mol Genet 19:3043-3052. doi:10.1093/hmg/ddq209

147. Yu-Wai-Man P, Spyropoulos A, Duncan JH, Guagdano JV, Chinnery PF (2016) A multiple sclerosis-like disorder in patients with OPA1 mutations. Ann Clin Trans Neurol. doi:10.1002/acn3.323

148. Yu-Wai-Man P, Votruba M, Moore AT, Chinnery PF (2014) Treatment strategies for inherited optic neuropathies: past, present and future. Eye (Lond) 28:521-537. doi:10.1038/ eye.2014.37

149. Zuchner S, De Jonghe P, Jordanova A, Claeys KG, Guergueltcheva V, Cherninkova S, Hamilton SR, Van Stavern G, Krajewski KM, Stajich J et al (2006) Axonal neuropathy with optic atrophy is caused by mutations in mitofusin 2. Ann Neurol 59:276-281. doi:10.1002/ana.20797

150. Zuchner S, Mersiyanova IV, Muglia M, Bissar-Tadmouri N, Rochelle J, Dadali EL, Zappia M, Nelis E, Patitucci A, Senderek J et al (2004) Mutations in the mitochondrial GTPase mitofusin 2 cause charcot-marie-tooth neuropathy type $2 \mathrm{~A}$. Nat Genet 36:449-451. doi:10.1038/ng1341 